\title{
Bacterial Carbon Storage to Value Added Products
}

\author{
Christopher J. Brigham', Kazuhiko Kurosawa1', ChoKyun Rha² and Anthony J. Sinskey 1,3,4*
}

${ }^{1}$ Department of Biology, Massachusetts Institute of Technology, 77 Massachusetts Avenue, Cambridge, MA 02139

${ }^{2}$ Biomaterials Science and Engineering Laboratory, Massachusetts Institute of Technology, 77 Massachusetts Avenue,Cambridge,MA 02139

${ }^{3}$ Engineering Systems Division, Massachusetts Institute of Technology, 77 Massachusetts Avenue, Cambridge, MA 02139

${ }^{4}$ Health Sciences Technology Division, Massachusetts Institute of Technology, 77 Massachusetts Avenue, Cambridge, MA 02139

\begin{abstract}
Microorganisms have evolved different systems for storing carbon during times of stress. In the cell's natural environment, the stored carbon can then be utilized for growth when other nutrients are in better supply. Storage of carbon and other nutrients is ubiquitous throughout the prokaryotic and eukaryotic domains of life. These carbon storage molecules have great industrial importance. They can be useful as value-added products, as either biopolymers or biofuels, and cells are grown in large quantities and these compounds are harvested, usually as a replacement for a petroleum-based product. Nowadays, entire industries have been generated based on the production and utilization of these compounds. We focus on two bacteria that could be considered paradigms of their particular carbon storage strategy: Ralstonia eutropha and Rhodococcus opacus. R. eutropha has been well-studied as a polyhydroxyalkanoate (bioplastic) producer and $R$. opacus is a model bacterium for high yield triacylglycerol (TAG) production for biofuels. Both species produce carbon storage molecules that can potentially diminish our reliance on fossil-based petroleum. However, in both cases, there are challenges that must be overcome before profitable production schemes are established using these organisms. We explore the previous and current works to address these challenges in this review.
\end{abstract}

Keywords: Carbon storage; Polyhydroxyalkanoate; Triacylglycerol; Carbon/Nitrogen ratio

\section{Introduction}

Concerns about dwindling petroleum reserves have sparked worldwide concern, especially considering that the largest oil reserves tend to be located in unstable regions of the globe. As consumers of petroleum products for fuel and chemical needs, it is in our best interest to develop an inexpensive, renewable process for synthesis of bio-based fuels and other chemicals (e.g. plastics). As fuels and polymers are usually carbon-based, we can turn to organisms that are masters of carbon storage for this endeavor. Bacteria are capable of storing carbon in various forms during stress conditions. A well-studied family of carbon storage molecules is the polyhydroxyalkonoates (PHAs), which are known to exhibit properties of petroleum-based plastics $[1,2]$. Bacteria are also capable of storing carbon in the form of triacylglycerols (TAGs) $[3,4]$, which is a less well-known process, but is rapidly gaining recognition as a biofuel production scheme. To compete with petroleum products, biofuel and bioplastics production must be efficient and cost-effective. Many researchers in both academia and industry have produced pilot plant or industrial scale PHA production processes, but the cost of the polymer product is still high when compared to petroleum-based plastics. In many of these cases, Ralstonia eutropha, the model organism for PHA biosynthesis, or a recombinant Escherichia coli strain are used. Less is known about industrial TAG productions using bacteria, although one organism Rhodococcus opacus strain PD630 stands out as being an efficient TAG accumulating organism. In this paper, we discuss the state of PHA and TAG production processes, namely how we turn bacterial carbon storage molecules into valueadded products. Since the study of bacterial TAG production is still in its early stages, we offer some recent data in support of the quest to find an inexpensive process to produce the target molecule, with the goal of competing with petroleum products.

\section{Polyhydroxyalkanoates}

Ecology of valuable storage polyesters: Nutrient storage systems have evolved throughout nature as a stress survival mechanism.
Prokaryotes can store carbon for later use in different forms, as glycogen [5], as polyhydroxyalkanoates (PHAs) [6], and as triacylgycerols (TAGs) [7]. In nature, organisms store carbon when other nutrients are in short supply (i.e. unbalanced growth) and utilize these stores in carbon-sparse conditions. Since early in history, humans have made use of other organisms' carbon stores as food (plant oils and starches), fuel (whale oil), cosmetics (coconut oil, palm kernel oil), and other applications. In recent times, we are turning to microorganisms to rapidly produce carbon storage products for our own use. One well-studied example of carbon storage molecules becoming value added products is the aforementioned PHA. Several species of microorganisms have been characterized to express PHA production enzymes $[2,8,9]$. Intracellular PHA stores assist in survival of the organism when nutrients are sparse. In some cases, free-living, PHAproducing bacteria can outcompete non-PHA producers for the same niche [10]. PHA is polymerized by microbial cells and stored in dense, protein-covered inclusion bodies termed granules. In general, there are two types of PHAs, based on the monomer content: short chainlength, or scl-PHA, containing the 4 carbon 3-hydroxybutyrate (3HB) and/or the 5 carbon 3-hydroxyvalerate (3HV) monomers; and medium chain-length, or mcl-PHA, containing monomers of chain lengths greater than 6 carbons, including 3-hydroxyhexanoate $(3 \mathrm{HHx}, 6$ carbons), 3-hydroxyoctanoate (3HO, 8 carbons), and other monomers of longer chain length than $3 \mathrm{HHx}$. There are at least two distinct

*Corresponding author: Christopher J. Brigham Department of Biology, Massachusetts Institute of Technology, 77 Massachusetts Avenue, Cambridge, MA, USA. Tel: +1-617-253-6721, Fax: +1-617-253-8550; E-mail: asinskey@mit.edu

Received September 23, 2011; Accepted December 01, 2011; Published December 062011

Citation: Brigham CJ, Kurosawa K, Rha C, Sinskey AJ (2011) Bacterial Carbon Storage to Value Added Products. J Microbial Biochem Technol S3:002. doi:10.4172/1948-5948.S3-002

Copyright: @ 2011 Brigham CJ, et al. This is an open-access article distributed under the terms of the Creative Commons Attribution License, which permits unrestricted use, distribution, and reproduction in any medium, provided the original author and source are credited 
metabolic pathways for microbial PHA biosynthesis. For scl-PHA like polyhydroxybutyrate ( $\mathrm{PHB})$, two acetyl-CoA molecules are ligated to form acetoacetyl-CoA, and the acetoacetyl-CoA is reduced to form $\beta$-hydroxybutyryl-CoA. The $\beta$-hydroxybutyryl-CoA molecule then acts as a monomer substrate for the PHA synthase, and is incorporated into the nascent polymer chain by a thioesterase reaction taking place at the active site of the enzyme, and the Coenzyme-A is released [11]. Figure 1 shows a schematic of PHA production and intermediates starting with acetyl-CoA. The polymerization pathway shown here is typical for PHB production in the bacterium Ralstonia eutropha strain H16 (wild type), using a variety of carbon substrates. $R$. eutropha is a soil and fresh water dwelling bacterium that has been considered the model organism for PHA biosynthesis, as it can produce up to $80 \%$ of its cell dry weight as PHA during nitrogen limitation $[6,12]$. Monomers for PHA production can also be produced from intermediates of fatty acid $\beta$-oxidation. Fatty acid breakdown via $\beta$-oxidation produces 3 -hydroxyacyl-CoA which can be used as a monomer for mcl-PHA production. However, since 3-hydroxyacyl-CoA, the $\beta$-oxidation intermediate, is the $(S)$ form, it is unusable by the PHA synthase. The polymerizable (R)-3hydroxyacyl-CoA is produced by conversion of enoyl-CoA using an (R)-specific enoyl-CoA hydratase, often termed PhaJ [13,14]. For both scl- and mcl-PHA, cells synthesize and store polymer in intracellular inclusion bodies, called granule, surrounded by proteins (Figure 2). These proteins facilitate PHA metabolism, protect the granule from coalescence, and separate the hydrophobic polymer from the aqueous cytoplasm. By far the most abundant protein present on the PHA granule is the phasin (PhaP1), so named because of its analogous function to olesins that surround TAG inclusion bodies in plants [15]. The PhaP1 phasin has been shown to cover anywhere from $27-54 \%$ of the PHA granule surface in R. eutropha [16]. Other granule associated proteins include: the PHA synthase, $\mathrm{PhaC}$ [17]. The regulatory protein, PhaR $[12,18,19]$. and depolymerase enzymes, PhaZs [20]. Figure 2 illustrates PHA granule formation in R. eutropha. Recently, additional granule associated proteins have been discovered in R. eutropha [21], including a dual-function granule associated protein that also binds to the nucleoid region of the cell [22]. This newly discovered protein, PhaM, appears to have functional homology to the lipid body associated protein TadA from Rhodococcus opacus [23]. PhaM was independently discovered by our laboratory (Cho, et al. manuscript in preparation) attached to residual PHB in a highly purified sample of epitope tagged PhaC protein, isolated from recombinant $R$. eutropha. The association of many proteins, each having different functions in the PHA production cycle, suggests that the PHA granule is a complex organelle that allows for optimal carbon sequestration and mobilization, depending on nutrient availability in the extracellular milieu [8].

\section{Polyhydroxyalkanoates as a value added product: biodegradable plastics}

Since before the first patents for commercial PHA production were issued to W.R. Grace and Company in the 1960's, many individuals have recognized the commercial potential of these biopolymers. Several types of PHA biopolymers have thermal and mechanical properties that rival

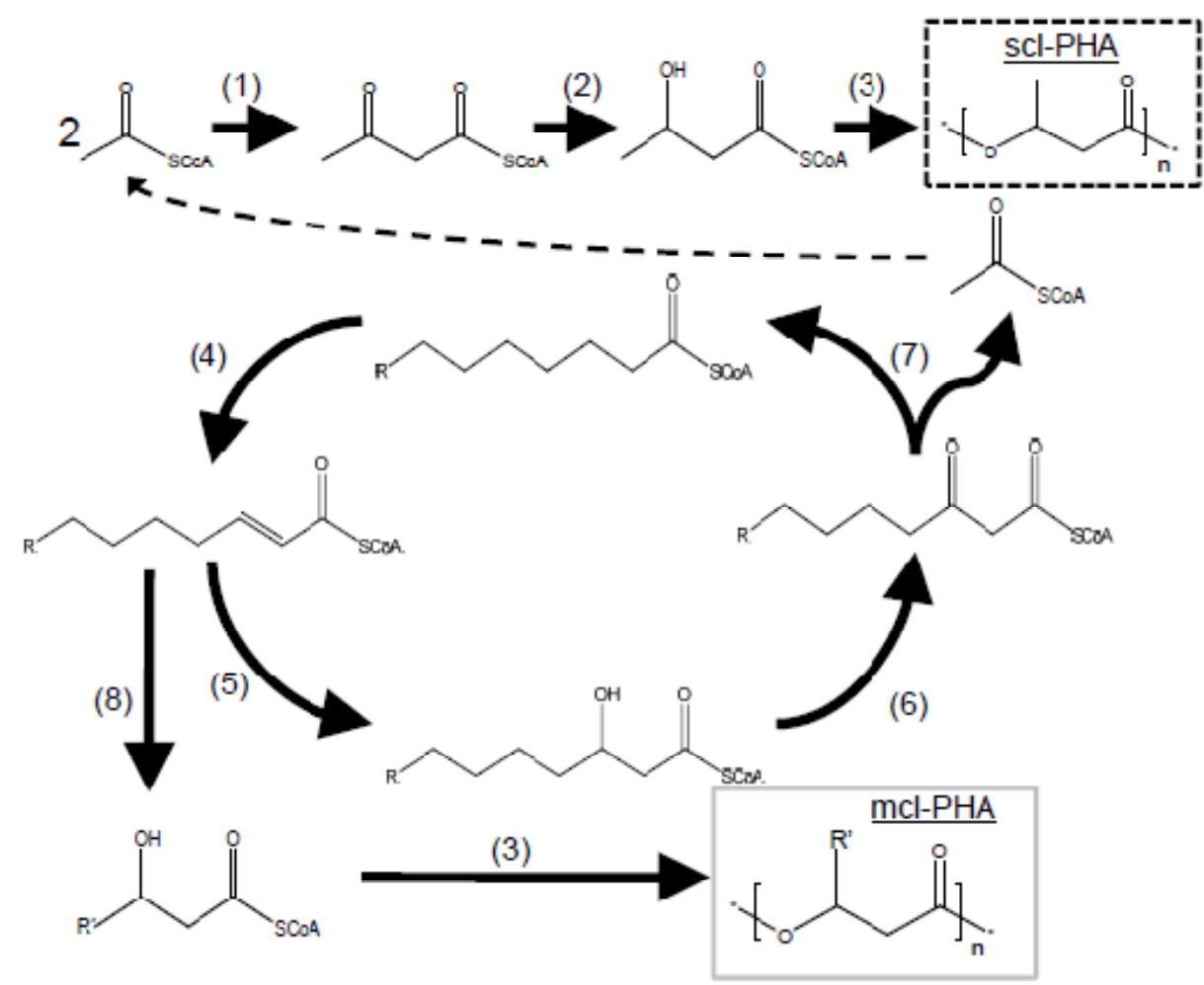

Figure 1: A schematic of microbial PHA production pathways. For scl-PHA, 2 molecules of acetyl-CoA are ligated by a $\beta$-ketothiolase (1) to form acetoacetyl-CoA, which is reduced by acetoacetyl-CoA reductase (2) to form 3-hydroxybutyryl-CoA (3HB-CoA). The 3HB-CoA is polymerized by a PHA synthase enzyme (3) to produce PHB (black dashed box). Acetyl-CoA for PHB biosynthesis can be produced by a turn of the fatty acid $\beta$-oxidation cycle (enzymes 4-7). Substrates for mcl-PHA can also come from $\beta$-oxidation, via an (R)-specific enoyl-CoA hydratase (8). These medium chain-length hydroxyacyl-CoA molecules are polymerized by a PHA synthase (3) to produce mcl-PHA (grey box). Medium chain-length monomers can also be produced through fatty acid biosynthesis (not shown). Enzyme designations: fatty acyl-CoA dehydrogenase (4), 2-enoyl-CoA hydratase (5), 3-hydroxyacyl-CoA dehydrogenase (6), $\beta$-ketothiolase (7). 
Citation: Brigham CJ, Kurosawa K, Rha C, Sinskey AJ (2011) Bacterial Carbon Storage to Value Added Products. J Microbial Biochem Technol S3:002. doi:10.4172/1948-5948.S3-002

Page 3 of 13

those of petroleum-based thermoplastics. A summary of thermal and mechanical properties of various PHAs is found in Table 1. These PHAs can substitute for petrochemical plastics in many different applications. The company Metabolix, based in Cambridge, MA, USA, is currently the world's largest industrial producer of PHA (www.metabolix.com). Telles, a joint venture between Metabolix and Archer Daniels Midland, will produce large quantities of the copolymer poly(3-hydroxybutyrateco-4-hydroxybutyrate), or $\mathrm{P}(3 \mathrm{HB}-c o-4 \mathrm{HB})$, from corn sugar using engineered bacterial strains. Other PHA producing companies are in operation all over the world, such as Tianan Biologic Material in China and Biocycle in Brazil. Recently, a pilot scale bioplastic production plant was opened in Malaysia to produce PHA from palm oil products using engineered R. eutropha [24].
What makes a biopolymer suitable for industrial production? The PHA polymer must have favorable thermal and physical properties, so it can replace petroleum-based plastics like polypropylene. As seen in Table 1, the polyhydroxybutyrate (PHB) homopolymer is very stiff and brittle, suggesting a limited range of applications. PHA copolymers exhibit preferable properties (Table 1), likely due to decreased crystallinity as a result of interactions of two different chain-length monomers in the polymer [25]. Copolymers $\mathrm{P}(3 \mathrm{HB}-c o-4 \mathrm{HB}), \mathrm{P}(3 \mathrm{HB}-$ co-3HHx $)(3 \mathrm{HHx}=3$-hydroxyhexanoate $)$, and $\mathrm{P}(3 \mathrm{HB}-c o-3 \mathrm{HV})(3 \mathrm{HV}=$ 3-hydroxyvalerate) have been well-studies for their potential to replace petrochemical polymers in many different applications. These polymers are bio-based, biodegradable, and biocompatible [26-30]. Each type of copolymer is attractive as petroleum-based polymer substitutions, and large quantities are being produced commercially today.

b

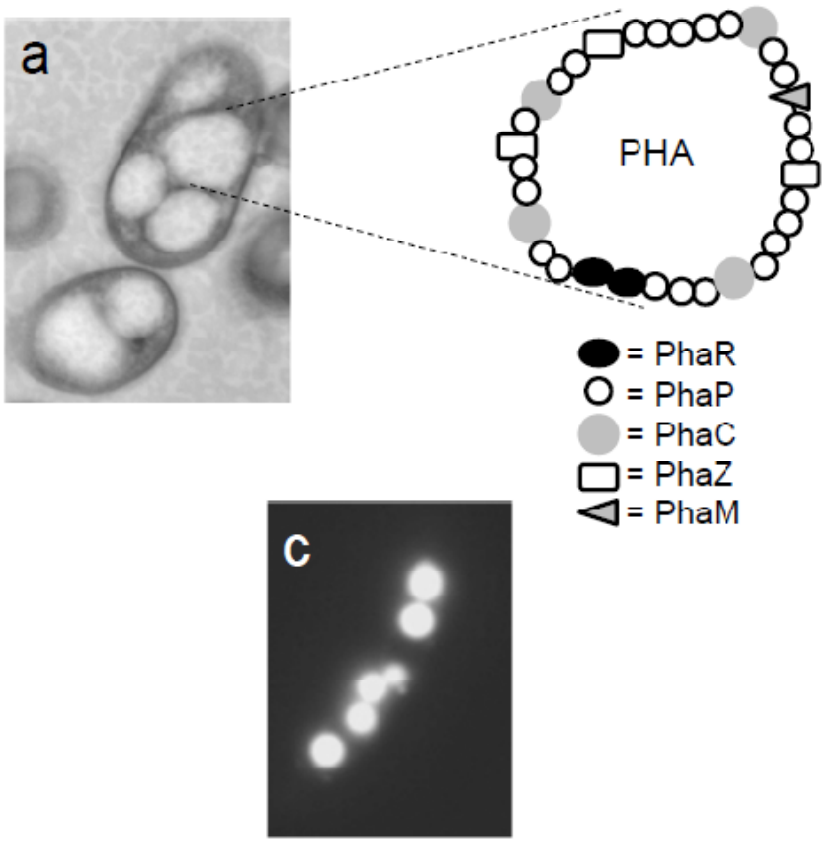

Figure 2: (A) Transmission electron micrograph of $R$. eutropha $\mathrm{H} 16$ cells containing PHA granules. (B) Schematic representation of a PHA granule in $R$. eutropha. Enzyme designations: PhaR = Regulator of PhaP expression; PhaP = Phasin protein; PhaC = PHA synthase; PhaZ = PHA depolymerase; PhaM = New DNA-binding, granule associated protein, as described in [22]. (C) Fluorescent micrograph of $R$. eutropha Re2058/pCB113 [24] grown for $24 \mathrm{~h}$ in minimal (PHA production) medium with palm oil as the sole carbon source [43]. $\mathrm{P}(\mathrm{HB}-\mathrm{CO}-\mathrm{HHx})$ granules are stained with Nile red.

\begin{tabular}{|c|c|c|c|c|c|c|c|c|}
\hline Polymer & $\mathrm{T}_{\mathrm{m}}\left({ }^{\circ} \mathrm{C}\right)$ & $\mathrm{T}_{\mathrm{g}}\left({ }^{\circ} \mathrm{C}\right)$ & $\begin{array}{l}\text { Young's } \\
\text { (GPa) }\end{array}$ & Modulus & $\begin{array}{l}\text { Tensile } \\
\text { (MPa) }\end{array}$ & Strength & $\begin{array}{l}\text { Elongation to break } \\
(\%)\end{array}$ & Reference \\
\hline PHB & 177 & 4 & 3.5 & & 43 & & 5 & {$[129,130]$} \\
\hline $\mathrm{P}(\mathrm{HB}-\mathrm{co}-10 \mathrm{~mol} \% \mathrm{HHx})$ & 127 & -1 & $\mathrm{nd}^{\mathrm{a}}$ & & 21 & & 400 & [129] \\
\hline $\mathrm{P}(\mathrm{HB}-\mathrm{co}-12 \mathrm{~mol} \% \mathrm{HHx})$ & 103 & -2 & 0.5 & & 10 & & 130 & [131] \\
\hline P(HB-co- 15mol\% HHx) & 115 & 0 & $\mathrm{nd}^{\mathrm{a}}$ & & 23 & & 760 & [129] \\
\hline $\mathrm{P}(4 \mathrm{HB})$ & 53 & -48 & 0.15 & & 104 & & 1000 & [132] \\
\hline $\mathrm{P}(3 \mathrm{HB}-\mathrm{co}-12 \mathrm{~mol} \%$ 4HB $)$ & 124 & -4 & 0.54 & & 25 & & 630 & [131] \\
\hline LDPE $^{\mathrm{b}}$ & 130 & -30 & 0.2 & & 10 & & 620 & [130] \\
\hline Polypropylene & 176 & -10 & 1.7 & & 38 & & 400 & [130] \\
\hline Polystyrene & 240 & 100 & $n d^{a}$ & & $n^{a}$ & & $n d^{a}$ & {$[130]$} \\
\hline
\end{tabular}

and $=$ not determined in the indicated study

'Low density polyethylene

Table 1: Thermal and mechanical properties of PHA polymers and petrochemical polymers. 


\section{Fermentative production of PHA copolymers: progress}

Production of PHAs on an industrial scale requires that many challenges be overcome. Importantly, high cell density cultivation is a prerequisite to maximizing volumetric productivity of microbial fermentation. In many cases, an Escherichia coli strain is employed for polymer biosynthesis [31-33]. As wild-type E. coli is not capable of producing 3-hydroxyacyl-CoAs (3HA-CoA) de novo for polymer synthesis, the PHA production pathway must be supplied heterologously. Some advantages of using a recombinant $E$. coli strain are the rapid growth rate and the fact that PHA biosynthesis is not controlled by nutrient limitation in a recombinant strain, and thus cells will produce PHA concomitant with growth. An E. coli strain expressing PHA biosynthesis genes and overexpressing the cell division protein FtsZ, accumulated PHB to a concentration of $104 \mathrm{~g} / \mathrm{L}$ in fed batch conditions [33]. A PHB concentration of $>140 \mathrm{~g} / \mathrm{L}$ was obtained using E. coli expressing PHA production genes from Alcaligenes latus, in fed batch culture [32]. The same strain was used in fed batch culture with propionic acid feeding and $\mathrm{P}(\mathrm{HB}-\mathrm{co}-\mathrm{HV})$ was produced with a productivity of $>2.8 \mathrm{~g} / \mathrm{L} / \mathrm{h}$ [31]. Recombinant $E$. coli has also been utilized for $\mathrm{P}(\mathrm{HB}-c o-\mathrm{HHx})$ production, with final productivities of $\sim 0.5$ g PHA/L/h [34]. R. eutropha is also an attractive species for industrial PHA production. Since the bacterium is a native PHA producer, the cellular machinery and regulatory systems are already in place to produce large quantities of PHA. Also, R. eutropha is capable of utilizing a wide array of carbon sources for growth and polymer biosynthesis, including sugars $[16,35,36]$, organic acids $[37,38]$, plant oils and fatty acids [39-43], and $\mathrm{CO}_{2}[44,45]$. Thus, inexpensive feedstocks, such as agricultural and food processing wastes, unrefined natural products (e.g. plant oils), or concentrated $\mathrm{CO}_{2}$, can potentially be used to produce large amounts of polymer at competitive prices. High productivity (i.e. space time yield) of PHA is critical in industrial polymer production. Over the past decade, researchers have made many attempts to increase yields of biomass and with it, PHA. While for TAG production (see below), culture carbon/nitrogen $(\mathrm{C} / \mathrm{N})$ ratios are paramount for maximizing productivities, high PHA productivity cultures can result from nitrogen or phosphate (or other nutrient) limitation in cultures. PHB productivities of over $1.0 \mathrm{~g} / \mathrm{L} / \mathrm{h}$ were observed when $R$. eutropha was grown in fed batch culture using corn steep liquor [46,47]. Twostage culture systems have also been examined for maximization of PHB production by $R$. eutropha, where the initial stage served as cell growth, producing maximum biomass, and the second stage constituted PHB accumulation. These two stage cultures exhibited a maximum productivity of $1.2 \mathrm{~g} / \mathrm{L} / \mathrm{h}$ with $>70 \%$ PHB per cell dry weight [48]. Typically with PHA production in $R$. eutropha strains, nitrogen plays the role of limiting nutrient to trigger polymer biosynthesis. High productivity has been seen using phosphate limitation, also, with $>1.5$ g PHB/L/h [49].

While high productivity $\mathrm{PHB}$ production is a good method by which to demonstrate that efficient fermentations can be performed using $R$. eutropha, PHA copolymers are the more ideal fermentation product, given their more favorable properties (Table 1). Using an alternating feeding of sugar and propionic acid in $R$. eutropha fed batch culture, Madden and Anderson [50] show that a $\mathrm{P}(\mathrm{HB}-\mathrm{co}-\mathrm{HV})$ productivity of $>1.5 \mathrm{~g} / \mathrm{L} / \mathrm{h}$ can be obtained. The final $3 \mathrm{HV}$ content was $\sim 7.5 \mathrm{~mol} \%$ in this study [50]. Using a strain of $R$. eutropha expressing a heterologous PHA synthase (from Aeromonas caviae), $\mathrm{P}(\mathrm{HB}-\mathrm{co}-\mathrm{HHx}$ ) was produced using soybean oil as the sole carbon source, with a productivity of just over $1.0 \mathrm{~g} / \mathrm{L} / \mathrm{h}$. In this case, the $3 \mathrm{HHx}$ fraction of the polymer was $\sim 5 \mathrm{~mol} \%$ [41]. Recently, a novel strain of R. eutropha was designed that expressed a heterologous PHA synthase (from Rhodococcus aetherivorans), as well as a phaJ gene (from Pseudomonas aeruginosa) for conversion of fatty acid $\beta$-oxidation intermediates into $(R)-3 \mathrm{HA}$ CoA substrates for PHA biosynthesis [24]. Growth of this strain in fed batch fermentations using palm oil as the sole carbon source and urea as the nitrogen source resulted in $\mathrm{P}(\mathrm{HB}-\mathrm{co}-\mathrm{HHx})$ biosynthesis with a productivity of $>1.0 \mathrm{~g} / \mathrm{L} / \mathrm{h}$, and a $3 \mathrm{HHx}$ content of $\sim 17 \mathrm{~mol} \%$. In this work, PHA productivities of different feeding strategies were compared, with fed batch fermentation being the ideal fermentation procedure [43]. Other high density fermentations resulting in efficient production of $\mathrm{P}(\mathrm{HB}-\mathrm{co}-\mathrm{HHx})$ have been performed. Cultures of Aeromonas hydrophila produced $\mathrm{P}(\mathrm{HB}-\mathrm{co}-\mathrm{HHx})$ with a productivity of $\sim 1.0 \mathrm{~g} / \mathrm{L} / \mathrm{h}$, using fatty acids as the sole carbon source [51]. Large scale (20,000 L) fermentations were performed using A. hydrophila grown on glucose, with a $\mathrm{P}(\mathrm{HB}-c o-\mathrm{HHx})$ productivity of slightly greater than 0.5 [52]. In production of mcl-PHA, a productivity of $0.8 \mathrm{~g} \mathrm{PHA} / \mathrm{L} / \mathrm{h}$ was observed in fed batch culture of Pseudomonas putida grown on mixed sugars [53]. A productivity of 2.0 was achieved with high density P. putida cultures using phosphate limitation [54]. A summary of high yield PHAz production studies from the current literature is shown in Table 2.

\section{PHA production challenges}

While researchers have shown robust, scalable PHA production in several systems, there are still challenges that must be overcome. The challenges largely relate to producing PHA in an inexpensive manner so the price of the final product competes with petrochemical plastics. First, readily available and inexpensive feedstocks must be used for carbon substrates in growth and PHA production. $\mathrm{CO}_{2}$ is readily

\begin{tabular}{|c|c|c|c|c|c|c|}
\hline Production organism & Polymer produced & Carbon source & Biomass yield (g/L) & PHA yield $(g / L)$ & Productivity (g/L/h) & Reference \\
\hline E. coli & PHB & glucose & 194.1 & 141.6 & 4.6 & [32] \\
\hline R. eutropha & PHB & glucose & 164.0 & 121.0 & 2.4 & [46] \\
\hline R. eutropha & PHB & corn steep liquor & 281.0 & 232.0 & 3.1 & [47] \\
\hline R. eutropha & PHB & glucose & 208.0 & 139.0 & 3.1 & [49] \\
\hline E. coli & PHB & glucose & 149.0 & 104.0 & 2.1 & [33] \\
\hline R. eutropha & $\mathrm{P}(\mathrm{HB}-\mathrm{co}-\mathrm{HV})$ & glucose and propionic acid & 84.0 & 65.5 & 1.6 & [50] \\
\hline Aeromonas hydrophila & $\mathrm{P}(\mathrm{HB}-\mathrm{CO}-\mathrm{HHx})$ & oleic acid & 95.7 & 43.2 & 1.0 & [51] \\
\hline Aeromonas hydrophila & $\mathrm{P}(\mathrm{HB}-\mathrm{Co}-\mathrm{HH} \mathrm{x})$ & glucose and lauric acid & 50 & 25 & 0.5 & [52] \\
\hline E. coli & $\mathrm{P}(\mathrm{HB}-\mathrm{Co}-\mathrm{HH} \mathrm{x})$ & dodecanoic acid & 79.0 & 21.5 & 0.5 & [34] \\
\hline R. eutropha & $\mathrm{P}(\mathrm{HB}-\mathrm{Co}-\mathrm{HH} \mathrm{x})$ & palm oil & 140.0 & 104.0 & 1.1 & [43] \\
\hline Pseudomonas putida & mcl-PHA & sugar cane carbohydrates & 50.0 & 31.5 & 0.8 & [53] \\
\hline Pseudomonas putida & mcl-PHA & oleic acid & 141.0 & 72.6 & 1.9 & [54] \\
\hline
\end{tabular}

Table 2: Summary of high PHA yield fed batch fermentation studies 
available and has been used as the sole carbon source for producing PHA [44,45,55,56], but concentrating $\mathrm{CO}_{2}$ for use as carbon feedstock in an autotrophic fermentation, as well as the fermentation parameters themselves, present major challenges [55]. Recently, waste streams have been sought for use as nutrient sources in production of value added products, such as PHA [57-61] and TAGs [62]. Hassan and coworkers have constructed a method for producing PHA from organic acids resulting from digestion of processing sludge from palm oil mill effluent [60]. Polymer has also been produced from pure cultures using whey [61,63], beet molasses [64], inedible jatropha oil [42], and waste glycerol [58]. Many studies have been performed on PHA production using mixed cultures with bacterial species and strains often obtained from the same waste streams $[65,66]$. This production process typically involves enriching for PHA-producing cultures of microorganisms and propagating stable cultures before harvesting polymer [65]. Enriching a mixed culture for PHA producers can be performed by a microaerophilic-aerobic system, controlling oxygen content of the culture to select for PHA accumulating bacteria over those that accumulate glycogen [66-69] or "feast/famine" cycling (a.k.a. aerobic dynamic feeding), where PHA accumulating organisms are selected on the basis of their ability to utilize polymer as a nutrient $[66,70]$. The advantage to mixed cultures is that cultivation conditions do not necessarily have to be sterile, which will save on energy costs. Feedstocks also do not need to be pure, although acetate is often used as a carbon source to enrich for PHA producing bacteria [65,66]. However, there are challenges associated with mixed culture PHA production, including development of culture selection strategies towards higher PHA yields and productivities [65,66,71]. Since mixed cultures involve wild-type and some unknown or uncharacterized organisms, the type of PHA produced (e.g. PHB) may not be ideal for most applications, and the outcome of the process is at the mercy of the microbial input.

There are other downstream challenges for industrial PHA production. The harvesting of biopolymer from cells presents problems in the formulation of a cost-effective production process. Many different chemicals have been tested for polymer recovery, including $\mathrm{NaOH}$ [72], sodium hypochlorite [73], chloroform [74], methyl ethyl ketone (MEK), methyl isobutyl ketone (MIBK), ethyl aetate [25,75], and aqueous detergent solutions [76,77]. The most ideal compounds for PHA recovery are those that can be recycled, reused and easily separated from aqueous solutions. Of the chemicals listed above, MEK and MIBK show the most promise in recovering highly pure PHA from biomass (Riedel, et al., manuscript in preparation). Not all solvents will successfully recover all types of PHA. For example, MIBK is better suited for PHA containing longer chain-length monomers, and less effective with PHB (data not shown). Other recovery methods, such as: enzymatic digestion [78], controlled autolysis [79], and dissolvedair flotation [80], have been performed to extract PHA from biomass. It is doubtful that any of these alternative recovery methods would be preferable in an industrial setting.

\section{Polyhydroxyalkanoates - outlook}

Currently, PHAs are on the market as renewable, biodegradable alternatives to conventional plastic. PHA is being used in many household, industrial, and medical applications. Although PHA produced in large quantities is relatively inexpensive, it is still costlier than petroleum-based plastic. Production of PHA using waste streams, such as agricultural waste, milling waste, food processing waste or even concentrated $\mathrm{CO}_{2}$ emissions, will potentially help drive down costs and make PHA a more economically competitive polymer, compared to the traditional plastics. Furthermore, environmentally conscious methods of polymer recovery from cells, i.e. use of non-halogenated and recyclable solvents, are required to make bioplastic production a greener process. Since polyhydroxyalkanoates can be tailor-made to exhibit similar properties to petroleum-based plastic, a robust and cost-effective production process is needed to compete in the current plastics market. In some cases, this type of process is already in practice, advancing the bioplastics industry on a global scale.

\section{Triacylglycerols}

Triacylglycerols (TAGs) are storage lipids with a neutral and nonpolar nature that allows them to be stored in anhydrous environments, and the major storage molecules of fatty acids for energy utilization and the synthesis of membrane lipids in living organisms [81]. TAGs are esters in which three molecules of fatty acids are linked to glycerol, and these fatty acids may be all the same kind, all different kinds, or only two the same, and may include saturated or unsaturated fatty acids. The chain lengths of the fatty acids in naturally-occurring TAGs vary, but most contain 16 or 18 carbon atoms. Natural fatty acids found in animals and plants are typically composed of only even numbers of carbon atoms, reflecting the pathway for their biosynthesis from the two-carbon building-block acetyl CoA $[82,83]$. Bacteria, however, possess the ability to synthesize odd- and branched-chain fatty acids [4]. The physicochemical properties of TAGs depend on the nature of the fatty acids present, chain length and the degree to which their fatty acids are desaturated. TAGs have been exploited in versatile materials, such as oleochemicals, cosmetics and food applications, and have furthermore recently garnered attention due to an increasing interest in alternative fuels [84].

\section{Triacylglycerols for biofuel production}

It is known that the fatty acyl chains of TAGs are chemically similar to the aliphatic hydrocarbons that make up the bulk of the molecules found in gasoline and diesel $[85,86]$. Vegetable oil, composed primarily of triacylglycerols, was used to run the early diesel engines when it was invented over 120 years ago. With the advent of inexpensive and abundant petroleum, the development of the diesel engine has been based on the efficacy of petroleum-derived diesel fuel, and vegetable oil as a fuel source was sidelined for decades. In 1973, the Arab oil embargo signaled the start of a new era of petroleum shortages. Suddenly, with a four-fold increase in petroleum prices, the international interest in biofuels has since been rejuvenated. Since 1973, much of the development of alternative bio-based fuels was being enhanced in countries that have little to no internal petroleum resources [87]. Then, between 2003 and 2008, the price of oil steadily rose. The price of a barrel of crude oil on the New York Mercantile Exchange was $\$ 30$ in 2003 , reached $\$ 60$ by 2005 , and peaked at $\$ 147$ in 2008 (http://tfccharts.com/chart/QM/W). Thus, the instability of petroleum fuel costs, depleting petroleum reserve and heightened concern about the effects of increasing atmospheric $\mathrm{CO}_{2}$ levels are intensifying the research for renewable biofuels that could reduce our current consumption of fossil fuels [88]. In the last few decades, efforts in the development of bio-ethanol as an alternative fuel have resulted in significant success [89]. However, bio-ethanol has some limitations, such as low energy density, corrosiveness and high vapor pressure, which prevent its widespread utilization given the existing infrastructure [90]. One possible solution to the issue can be the exploitation of TAGs for the production of lipid-based biofuels. Different TAG-based bioprocesses can generate biofuels with different compositions and properties [84]. A representative of those is biodiesel, which is typically manufactured 
by transesterification of TAGs with an alcohol, usually methanol, in the presence of an alkaline catalyst and therefore constitutes monoalkyl esters of long-chain fatty acids such as fatty acid methyl esters (FAMEs) and fatty acid ethyl esters (FAEEs). From the mid-1980s to early 2000s, most of the research on biodiesel production has focused on vegetable oils from oleaginous plants [91]. It has been reported that using raw vegetable oils in diesel engines leads to the progression of many engine-related problems such as deposits, injector coking and piston ring sticking, and these effects can be reduced or eliminated through transesterification of vegetable oil to form methyl or ethyl esters [92]. Most of the biodiesel that is currently produced uses a varied range of vegetable oils (edible and non-edible), animal fats, used frying oil and waste cooking oil. Detailed reviews about biodiesel production are available in the literature $[87,91,93-95]$. The biodiesel has environmental advantages, such as low amounts of suspended particulate matter and low levels of sulfur dioxide in emissions when burned, and can be used in most diesel engines with little or no modification. However, some physical limitations have been pointed out when these molecules are used as the sole fuel and not as a blendstock due to the cold-flow properties [94-96], and reliable implementation standards from public and government agencies are still lacking. Another kind of biofuel, probably best termed "renewable diesel", which is produced from TAGs by a hydrodeoxygenation reaction in the presence of a catalyst, has been garnering much attention since the early 2000's [95]. The notable advantage of the process is its feedstock flexibility, showing that renewable diesel can be processed from a great variety of TAGcontaining feedstocks - weedy plants, animal fats, waste oils, algae and oleaginous microorganisms [97]. TAGs are converted to products such as kerosene, gasoline, jet and diesel fuels all comprising paraffinic hydrocarbons whereby the hydrocarbon chain length is controlled to provide a distribution that is identical in virtually all respects to commercially available petroleum-derived fuels [98]. Recently, an F-22 Raptor successfully flew at supercruise (i.e. supersonic speed without using afterburners) on a 50/50 blend of hydrotreated renewable jet fuel and conventional petroleum-based JP-8 [99]. From these points of view, presently, energy-rich TAG molecules have attracted great attention for developing environmental-friendly and high-quality lipidbased biofuels.

\section{Triacylglycerol production in bacteria}

TAG biosynthesis is widely distributed in nature and the occurrence of TAG as reserve compounds is widespread among plants, animals, yeast and fungi. In contrast, however, TAGs have not been regarded as common storage compounds in bacteria. Biosynthesis and accumulation of TAGs have been described only for a few bacteria belonging to the actinomycetes group, such as genera of Streptomyces, Nocardia, Rhodococcus, Mycobacterium, Dietzia and Gordonia, and, to a minor extent, also in a few other bacteria, such as Acinetobacter baylyi and Alcanivorax borkumensis $[3,100]$. The presence of TAGs as vacuoles in bacteria has already been reported in Mycobacterium and Streptomyces in the 1940s to 1960s [4]. The systematic study on the formation of TAGs during growth has been reported in the 1990s with Streptomyces sp [101]. Since the mid-1990's, TAG production in hydrocarbon-degrading strains of those genera has been frequently reported [102]. TAGs are stored in spherical lipid bodies as intracellular inclusions, with the amounts depending on the respective species, cultural conditions and growth phase. Commonly the important factor for the production of TAGs is the amount of nitrogen that is supplied to the culture medium. The excess carbon, which is available to the culture after nitrogen exhaustion, continues to be assimilated by the cells and, by virtue of oleaginous bacteria possessing the requisite enzymes, is converted directly into lipid. The compositions and structures of bacterial TAG molecules vary considerably depending on the bacterium and on the cultural conditions (especially carbon sources). The pioneering work of TAG production in bacteria has been published by Steinbüchel et al. [3,4]. In recent years, aspects of the physiology and biochemistry of bacterial TAG accumulation, and the molecular biology of the lipid inclusion bodies are being investigated by many researchers [62,103-105].

\section{Triacylglycerol production of Rhodococcus opacus PD630}

Many bacterial species do not usually accumulate significant amounts of TAGs, and the content is generally about $20-40 \%$ of dry mass. Among the oleaginous bacteria, Alvarez and coworkers have demonstrated that $R$. opacus PD630 (DSMZ 44193) grown on defined medium containing olive oil is capable of accumulating TAGs accounting for up to $87 \%$ of the cell dry weight (CDW) [7]. The strain was isolated from a soil sample collected at a gas-works plant in Germany, as an oleaginous hydrocarbon-degrading bacterium, and was also able to grow on long-chain-length alkanes, gluconate, acetate, fructose, propionate, phenyldecane and phenylacetic acid (among others) and could produce remarkably high amounts of TAGs intracellularly; more than the other bacteria when the cells were cultured on similar substrates under nitrogen-limiting conditions. It has been reported that $R$. opacus PD630 cultivated in fed-batch conditions on media containing sucrose and sugar beet molasses reached a cell density of $37.4 \mathrm{~g}^{-1} \mathrm{CDW}$ with fatty acid content of $51.9 \%$ of the CDW, suggesting that the fermentation on carbon sources from agricultural products can be applied for the biotechnological production of TAGs [106]. In order for "Second generation biofuel technologies" to be produced in a sustainable manner and to avoid the food-fuel conflict, lignocellulosic biomass must be developed as feedstocks for TAG production [107,108]. Lignocellulosic biomass embraces cellulose, a glucose polymer. However, TAG production of $R$. opacus PD630 on glucose as a carbon source had not been shown until recently, when we discovered that $R$. opacus PD630 has the rare capability of accumulating large amounts of TAGs in batch-cultivation containing high concentrations of glucose under defined conditions [109]. Hereinafter, we briefly describe the notable capability of this strain of establishing a cost-effective "consolidated bioprocess" for TAG production from lignocellulosic biomass.

\section{Fermentation of $R$. opacus PD630 with high glucose concentrations}

High-cell-density cultivation is a prerequisite to maximizing volumetric productivity of microbial fermentation [110]. In this case, the successful execution of the fermentation depends on the ability of the bacterial strain used to deal with stress imposed by high sugar concentrations [111]. The growth kinetics of R. opacus PD630 in flask cultures on a defined medium with initial glucose concentrations of 200, 250, 300 and $350 \mathrm{~g} \mathrm{l}^{-1}$ were examined at an initial inoculum of $1.0 \mathrm{OD}_{660}$. The strain grew well on media containing up to $300 \mathrm{~g} \mathrm{l}^{-1}$, reaching stationary phase after $48 \mathrm{~h}^{\text {on }} 200 \mathrm{~g} \mathrm{l}^{-1}, 72 \mathrm{~h}^{\circ} 250 \mathrm{~g} \mathrm{l}^{-1}$ and $96 \mathrm{~h}$ on $300 \mathrm{~g} \mathrm{l}^{-1}$, although growth was inhibited at the highest glucose concentration of $350 \mathrm{~g} \mathrm{l}^{-1}$, as shown in Figure 3. Thus, R. opacus PD630 can be an idealized candidate for industrial fermentations in which high concentrations of glucose are utilized, whereas our preliminary studies have shown the presence of high concentrations of $\left(\mathrm{NH}_{4}\right)_{2} \mathrm{SO}_{4}$ in the media results in a concomitant decrease of the storage of TAG in the cells. Previous reports have demonstrated that carbon storage in various 


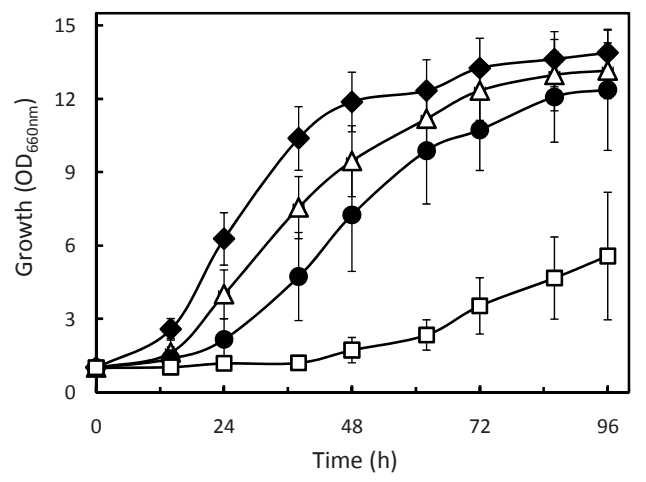

Figure 3: Growth of $R$. opacus PD630 on high glucose concentrations in flask cultures. Glucose concentrations tested in defined medium containing $1.4 \mathrm{~g} \mathrm{l}^{-1}$ $\left(\mathrm{NH}_{4}\right)_{2} \mathrm{SO}_{4}$ were $200 \mathrm{~g} \mathrm{l}^{-1}(\bullet), 250 \mathrm{~g} \mathrm{l}^{-1}(\square), 300 \mathrm{~g} \mathrm{l}^{-1}(\bullet)$ and $350 \mathrm{~g} \mathrm{l}^{-1}(\Delta)$. Initial inoculum density was adjusted to obtain an $\mathrm{OD}_{660}$ of 1.0 . The error bars represent the standard deviation of three separate replicates of each experiment.

bacteria is heavily influenced by the ratio of carbon to nitrogen $(\mathrm{C} / \mathrm{N})$. The effects of altering the $\mathrm{C} / \mathrm{N}$ ratio on TAG production of $R$. opacus PD630 were tested at the combination of various concentrations of glucose and $\left(\mathrm{NH}_{4}\right)_{2} \mathrm{SO}_{4}$, varying the amounts of glucose and $\left(\mathrm{NH}_{4}\right)_{2} \mathrm{SO}_{4}$ in the medium from 5 to $60 \mathrm{~g} \mathrm{l}^{-1}, 0.3$ to $2.8 \mathrm{~g} \mathrm{l}^{-1}$ respectively. As shown in Figure 4, when the $\left(\mathrm{NH}_{4}\right)_{2} \mathrm{SO}_{4}$ concentration was increased from 0.3 to $1.4 \mathrm{~g} \mathrm{l}^{-1}$ at concentrations of glucose from 20 to $40 \mathrm{gl}^{-1}$, the CDW and fatty acid production proportionally increased from 1.9-2.2 to 7.8-9.2 $\mathrm{g} \mathrm{l}^{-1}$ and 1.0-1.1 to 4.0-4.9 $\mathrm{g} \mathrm{l}^{-1}$, respectively, corresponding to a cellular fatty acid content of $50-55 \% \mathrm{CDW}$. Meanwhile, when the $\left(\mathrm{NH}_{4}\right)_{2} \mathrm{SO}_{4}$ concentration of the medium was increased further, to $1.7 \mathrm{~g} \mathrm{l}^{-1}$, the CDW and the fatty acid content decreased to $58-73 \%$ and $52-59 \%$, respectively, of those of the $1.4 \mathrm{~g} \mathrm{l}^{-1}\left(\mathrm{NH}_{4}\right)_{2} \mathrm{SO}_{4}$ cultures, resulting in a $57-67 \%$ drop in fatty acid production. When the final $\mathrm{pH}$ of the culture was measured, increasing $\left(\mathrm{NH}_{4}\right)_{2} \mathrm{SO}_{4}$ concentrations corresponded to lower final $\mathrm{pH}$. The broth supernatants of $R$. opacus PD630 grown in a defined medium containing more than $1.7 \mathrm{~g} \mathrm{l}^{-1}\left(\mathrm{NH}_{4}\right)_{2} \mathrm{SO}_{4}$ had a final $\mathrm{pH}$ value of 4.2-4.8. The results suggested that a decrease in $\mathrm{pH}$ inhibited growth and consequently decreased lipid production when $R$. opacus PD630 was grown under uncontrolled $\mathrm{pH}$ cultivations. Batchfermentations under controlled $\mathrm{pH}$ conditions allowed for an increase of the concentrations of glucose and $\left(\mathrm{NH}_{4}\right)_{2} \mathrm{SO}_{4}$ in the medium, resulting in a dramatic increase in TAG production [109]. When the critical operational $\mathrm{C} / \mathrm{N}$ ratio for maximum production of fatty acids was optimized using a response surface methodology based on the BoxWilson Central Composition Design, the design predicted that growing R. opacus PD630 in a defined medium with a $\mathrm{C} / \mathrm{N}$ of 17.8 containing $240 \mathrm{~g} \mathrm{l}^{-1}$ glucose and $13.4 \mathrm{gl}^{-1}\left(\mathrm{NH}_{4}\right)_{2} \mathrm{SO}_{4}$ would result in the maximum production of $25.1 \mathrm{~g} \mathrm{l}^{-1}$ of fatty acids (Figure 5). R. opacus PD630 grown in batch-fermentations with the predicted optimal conditions yielded $25.2 \mathrm{~g} \mathrm{l}^{-1}$ of fatty acids corresponding to $38 \%$ of the cell dry weight after $147 \mathrm{~h}$ of cultivation. The accumulated fatty acids in the cells consisted primarily of palmitic acid (28\%), oleic acid (25\%) and cis-10heptadecenoic acid (16\%). These results suggest that $R$. opacus PD630 has great potential as a TAG producer for developing industrial lipidbased biofuels on starchy lignocellulosic biomass that consist primarily of glucose polymers.
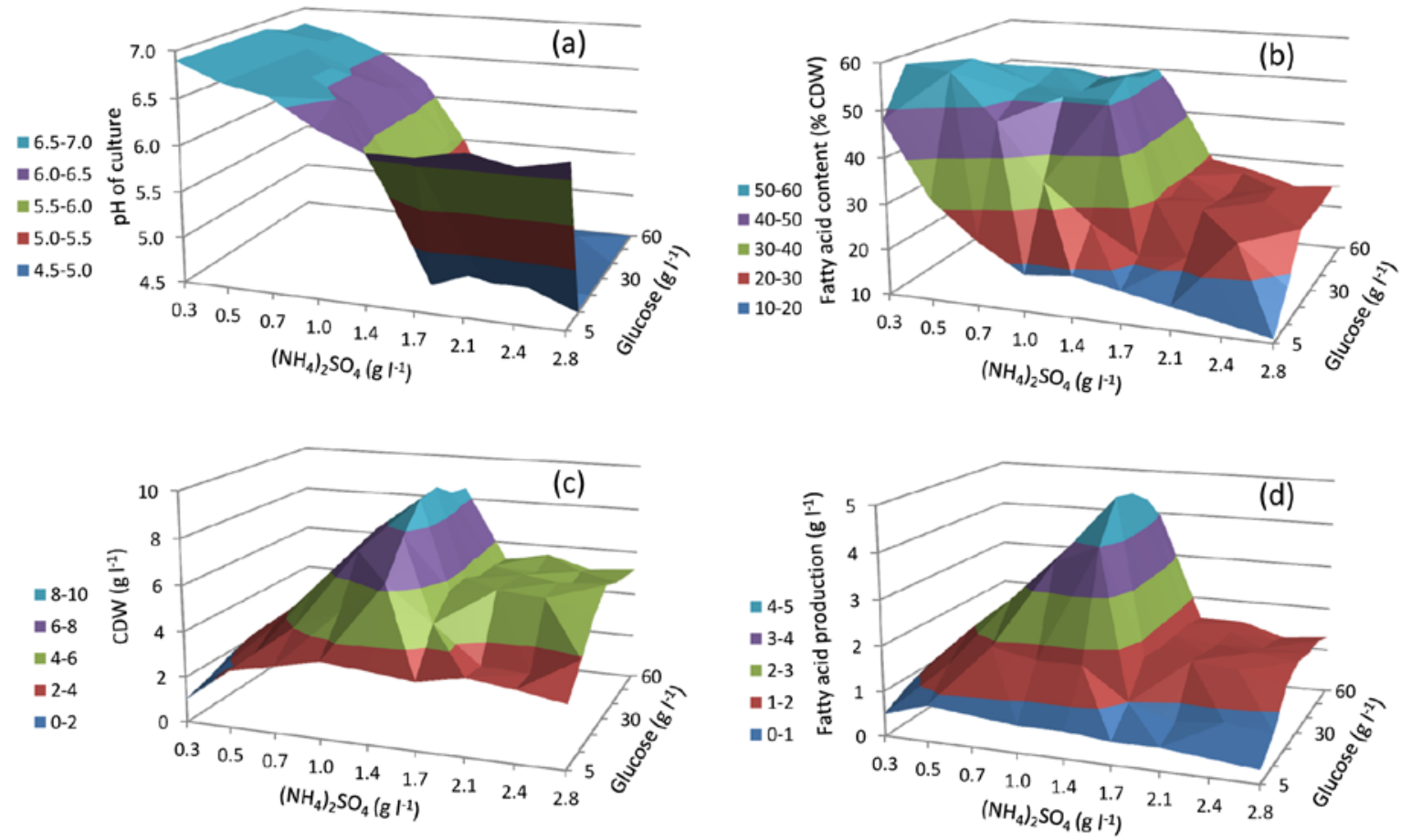

Figure 4: The effects of glucose and $\left(\mathrm{NH}_{4}\right)_{2} \mathrm{SO}_{4}$ concentrations on pH of culture (a), fatty acid content (b), CDW (c), and fatty acid production (d) by R. opacus PD630 in flask cultures. 
Citation: Brigham CJ, Kurosawa K, Rha C, Sinskey AJ (2011) Bacterial Carbon Storage to Value Added Products. J Microbial Biochem Technol S3:002. doi:10.4172/1948-5948.S3-002

\section{Fermentation of $R$. opacus PD630 on starchy lignocellulosic biomass-derived sugars}

The growth and lipid accumulation properties of R. opacus PD630 on saccharified solutions derived from corn silage were investigated. The corn silage homogenized by acid treatment was provided by Sweetwater Energy Inc. (Rochester, NY, USA). The undigested feedstock was adjusted to a $\mathrm{pH}$ of 5.0 and commercial enzymes (Novozymes, Bagsvaed, Denmark) consisting of $2 \mathrm{ml}$ Viscozyme $\mathrm{L}$ and $0.5 \mathrm{ml}$ Celluclast were added into $100 \mathrm{ml}$ of the suspension containing the silage of $67 \mathrm{~g} \mathrm{l}^{-1}$ as the dried mass. The saccharification was performed at $45^{\circ} \mathrm{C}$ with a rotational speed of $200 \mathrm{rpm}$. After $72 \mathrm{~h}$ of incubation, as shown in Figure 6, the sugar of the hydrolysate was composed of $32.2 \mathrm{~g} \mathrm{l}^{-1}$ glucose, $3.1 \mathrm{~g} \mathrm{l}^{-1}$ xylose, $0.7 \mathrm{~g} \mathrm{l}^{-1}$ arabinose and $3.6 \mathrm{~g} \mathrm{l}^{-1}$ other unidentified sugars, indicating that we are able to convert approximately $50 \%$ of the feedstock to monosaccharides. As it is known that the feedstock contains large quantities of starch, $0.5 \mathrm{ml}$ of glucoamylase (AMG 300L, Novozymes) was added into $100 \mathrm{ml}$ of the feedstock in a separate treatment, and the suspension was incubated at $45^{\circ} \mathrm{C}$ for $72 \mathrm{~h}$ at $200 \mathrm{rpm}$ (data not shown).

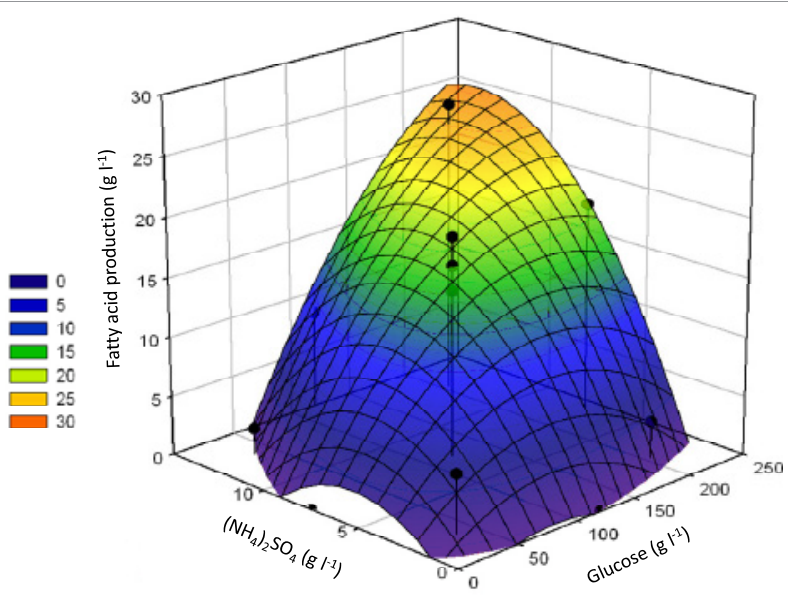

Figure 5: The response surface curve of the effect of glucose and $\left(\mathrm{NH}_{4}\right)_{2} \mathrm{SO}_{4}$ concentrations on fatty acid production by $R$. opacus PD630 in batch-culture fermentations (Curves: predicted value; points: experimental data).

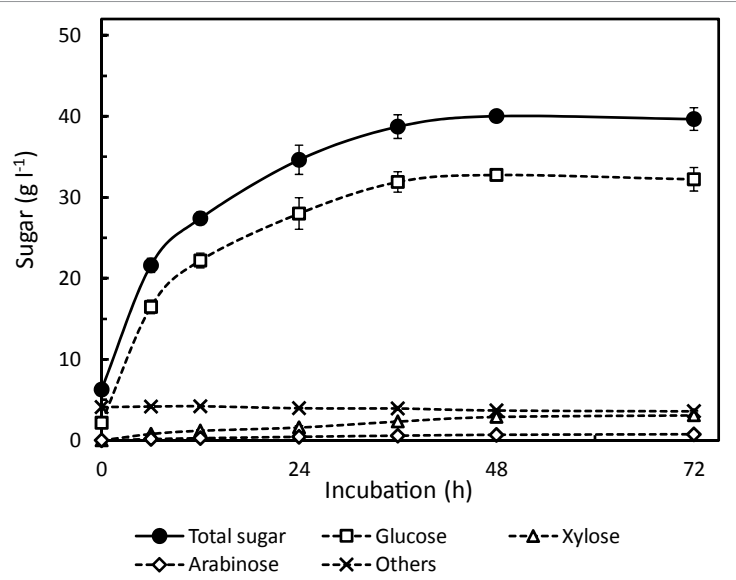

Figure 6: Saccharification of corn silage by commercial enzymes. The homogenized feedstock ( $67 \mathrm{~g} \mathrm{l}^{-1}$ of dried material) was adjusted to $\mathrm{pH} 5.0$, and Novozymes ( $2 \mathrm{ml}$ Viscozyme and $0.5 \mathrm{ml}$ Celluclast) were added into $100 \mathrm{ml}$ of the suspension, and hydrolyzed at $45^{\circ} \mathrm{C}$ at $200 \mathrm{rpm}$. The error bars represent the standard deviation of three independent replicates.

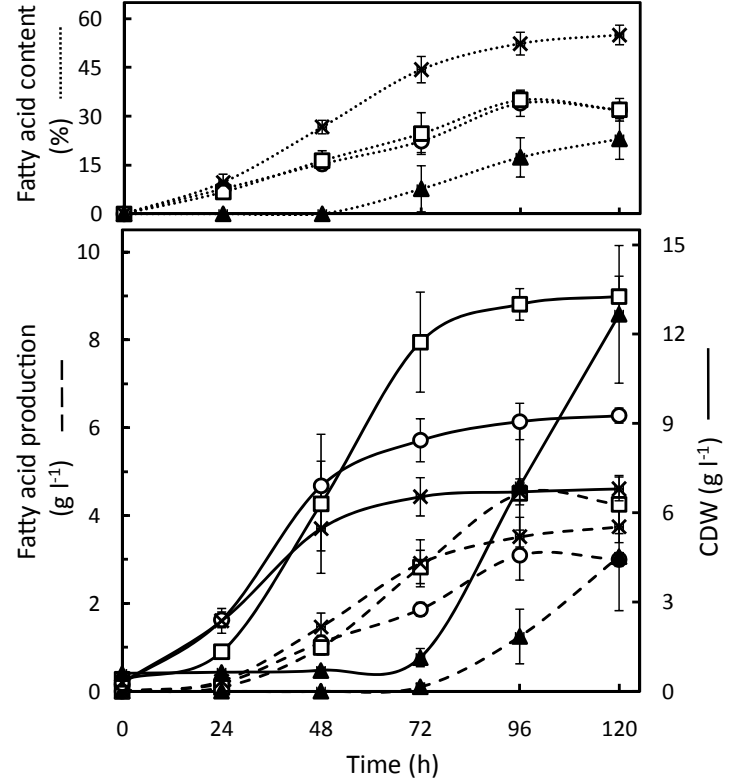

Figure 7: Growth and lipid production of $R$. opacus PD630 on various concentrations of the saccharified corn silage solution in flasks. The strain was inoculated in the saccharified $50 \%(\circ), 75 \%(\square)$ and $100 \%(\boldsymbol{\Delta})$ solutions and a defined medium $\left(\mathrm{x}\right.$ ) containing $18 \mathrm{~g} \mathrm{l}^{-1}$ glucose and $1 \mathrm{~g} \mathrm{l}^{-1}\left(\mathrm{NH}_{4}\right)_{2} \mathrm{SO}_{4}$ at an initial $\mathrm{OD}_{660}$ of 0.3 . A saccharified stock diluted $1: 1$ with water is termed " $50 \%$," and a saccharified stock diluted 3:1 with water is termed "75\%" (see text). The error bars represent the standard deviation of three independent replicates.

The HPLC data of the hydrolysate showed the presence of glucose as a principal sugar with more than $96 \%$ selectivity. Considering that $28 \mathrm{~g}$ $\mathrm{I}^{-1}$ of glucose was detected in the supernatant when glucoamylase alone was added into the feedstock suspension $\left(67 \mathrm{~g} \mathrm{l}^{-1}\right)$ and saccharified, it appeared that the feedstock contained approximately $35 \%$ starch.

The effects of concentrations of the saccharified corn silage solution on growth of $R$. opacus PD630 in flasks were tested. Depending on the desired conditions, the saccharified solution after $72 \mathrm{~h}$ of incubation shown in Figure 6 was adjusted to $\mathrm{pH} 7.2$ with $1 \mathrm{M} \mathrm{NaOH}$ and either diluted with deionized water or concentrated by freeze-drying. In examination of cell growth on the saccharified solution, use of a $100 \%$ stock for feeding resulted in growth inhibition, thus we used diluted stocks of 1:1 saccharified solution/water (termed "50\%") or $3: 1$ saccharified solution/water (termed " $75 \%$ "). As shown in Figure 7, PD630 started growing in a defined medium containing $18 \mathrm{~g} \mathrm{l}^{-1}$ glucose and $1 \mathrm{~g} \mathrm{l}^{-1}\left(\mathrm{NH}_{4}\right)_{2} \mathrm{SO}_{4}$ and in media containing $50 \%\left(20 \mathrm{~g} \mathrm{l}^{-1}\right.$ of fermentable sugars) and $75 \%$ ( $30 \mathrm{gl}^{-1}$ of fermentable sugars) levels of the saccharified solution after $24 \mathrm{~h}$ cultivation, and in undiluted solution ( 40 $\mathrm{g} \mathrm{l}^{-1}$ of fermentable sugars) after $72 \mathrm{~h}$ cultivation. Use of a concentrated solution (50 $\mathrm{g} \mathrm{l}^{-1}$ of fermentable sugars) resulted in a growth inhibitory effect on $R$. opacus PD630 (data not shown). The results suggested that the hydrolysate of corn silage apparently contains certain growth inhibitory compounds, as $R$. opacus cells are typically capable of growth using sugars as carbon sources. In addition, a clear difference in the percentage of fatty acids per CDW was observed between the defined medium and the saccharified solution fermentation. In the fermentation of defined medium containing $18 \mathrm{~g} \mathrm{l}^{-1}$ glucose and $1 \mathrm{gl}^{-1}\left(\mathrm{NH}_{4}\right)_{2} \mathrm{SO}_{4}$, the fatty acid content was more than $50 \%$ of the $\mathrm{CDW}$ at the stationary phase of growth after $96 \mathrm{~h}$ of cultivation; whereas in fermentation of the $50 \%$ saccharified solution composed of $16.1 \mathrm{~g} \mathrm{l}^{-1}$ glucose and 3.7 
$\mathrm{g} \mathrm{l}^{-1}$ other sugars, the fatty acid content represented $34.3( \pm 4.0) \%$ of $\mathrm{CDW}$ at $96 \mathrm{~h}$ of cultivation and gradually decreased after reaching the maximum fatty acid accumulation. This result using the saccharified solution suggests that the $\mathrm{C} / \mathrm{N}$ ratio of the solution was unbalanced, with an excess of nitrogen source over carbon source.

The effect of the addition of glucose on lipid production by $R$. opacus PD630 grown on the saccharified solution in flasks was also examined. PD630 was grown on the $75 \%$ saccharified solution supplemented with 10, 20 or $30 \mathrm{~g} \mathrm{l}^{-1}$ of glucose, or without, and a time course of fatty acid production in flask cultures was investigated. As shown in Figure 8, fermentations following amendment with additional glucose into the $75 \%$ solution containing $30 \mathrm{~g} \mathrm{l}^{-1}$ of sugars resulted in a significant increase in the fatty acid production and the fatty acid content of the CDW as compared with that on the solution without additional glucose. After $120 \mathrm{~h}$ of cultivation, the CDW and the fatty acid production of PD630 grown in the solution without additional glucose were $14.2( \pm 1.3) \mathrm{g} \mathrm{l}^{-1}$ and $4.4( \pm 0.7) \mathrm{g}^{l^{-1}}$ representing a fatty acid content of $31.0( \pm 2.0) \%$ CDW, respectively, whereas the CDW of 16.9 $( \pm 1.1) \mathrm{gl}^{-1}$ and the fatty acid production of $8.9( \pm 0.3) \mathrm{gl}^{-1}$ corresponding to a fatty acid content of $52.7( \pm 2.1) \% \mathrm{CDW}$ were maximum when 20 $\mathrm{g} \mathrm{l}^{-1}$ of glucose was added into the solution. The fatty acid content in the solution supplemented with $20 \mathrm{~g} \mathrm{l}^{-1}$ of glucose were equal to that [55.0 $( \pm 3.0) \% \mathrm{CDW}]$ in a defined medium containing $18 \mathrm{~g} \mathrm{l}^{-1}$ glucose and $1 \mathrm{~g} \mathrm{l}^{-1}\left(\mathrm{NH}_{4}\right)_{2} \mathrm{SO}_{4}$ (Figure 5). The identity of the lipids and the fatty acid composition profile of $R$. opacus PD630 grown in the saccharified solutions were very similar to those of the strain grown in the defined medium (data not shown). Figure 9 shows lipid body morphology of $R$. opacus PD630 grown in a 75\% saccharified silage solution supplemented with $20 \mathrm{~g} \mathrm{l}^{-1}$ of glucose for $120 \mathrm{~h}$ in flask cultures. $R$. opacus PD630 grown in the saccharified solution has a multitude of small lipid bodies

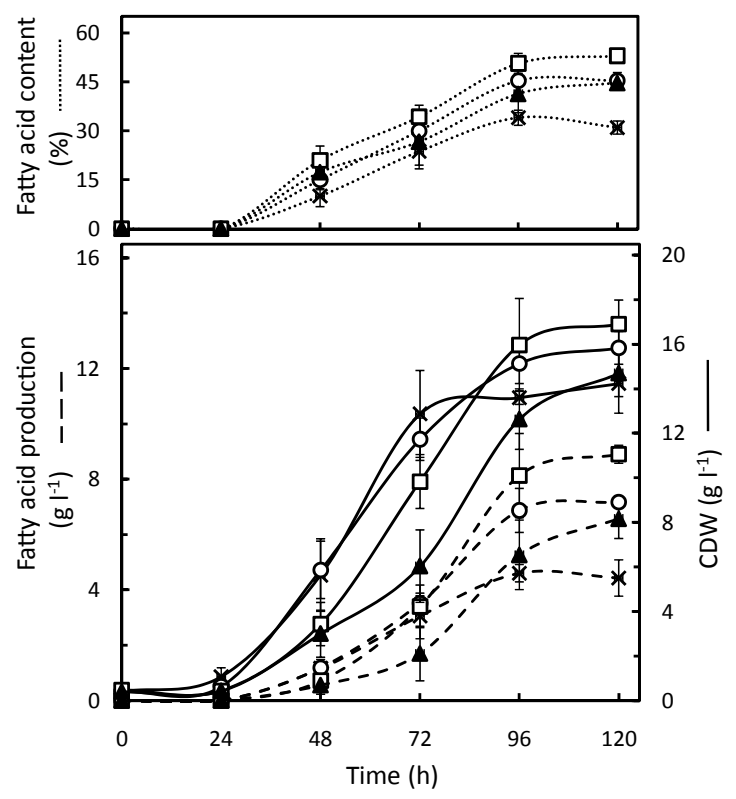

Figure 8: Effect of additional glucose on lipid production by R. opacus PD630 grown on the saccharified corn silage solution in flasks. The strain was inoculated in the saccharified $75 \%$ solution supplemented with 10 (०), 20 () or $30(\mathbf{\Delta}) \mathrm{g} \mathrm{l}^{-1}$ of glucose, or without ( $\mathrm{x}$ ), at an initial $\mathrm{OD}_{660}$ of 0.3 . The error bars represent the standard deviation of three independent replicates.

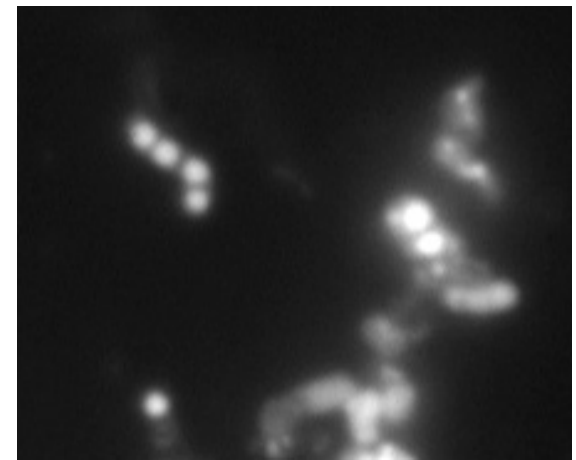

Figure 9: Fluorescent micrograph of $R$. opacus PD630 cells stained with the lipophilic fluorophore Nile Red. Cells were grown in minimal medium containing a saccharified silage solution for $120 \mathrm{~h}$ in a flask culture.

which almost completely fill the cytoplasm of the cells, which is similar to what is seen in cells grown in defined medium.

These results indicated that saccharified solution from corn silage contains sufficient nutrients for TAGs production by $R$. opacus PD630, although the carbon to nitrogen ratio $(\mathrm{C} / \mathrm{N})$ in the solution composition is optimized for high lipid production.

\section{Perspectives of bacterial TAG for lipid-based biofuels}

Many countries are navigating their attention to the development of clean and sustainable energy sources [88,112]. Among the various feasible sources of renewable energy, advanced liquid (lipid-based) fuels such as biodiesel and bio-jet fuel are of greatest interest and are expected to play a crucial role in the global energy infrastructure in the future [94-96]. TAGs are utilized as precursors for the production of lipid-based biofuels, and currently the main sources for TAG are vegetable oils, animal fats or waste cooking oils. The biofuels produced from crop seeds have come under major scrutiny due to the food vs. fuel competition problem [107]. Microalgae are currently viewed as an attractive feedstock for lipid-based fuels due to their ability to produce substantial amounts of TAG. However, current studies with TAG production by microalgae, using the best available strains and cultivation methods, have resulted in considerably lower yields than the theoretical maximum [113-115]. Presently, the limited supply of bioresources for obtaining TAGs is a major bottleneck for production of lipid-based biofuels, in spite of the favorable impacts that commercialization of TAG-based biofuels could provide. One alternative method to produce TAGs is to utilize heterotrophic organisms which produce TAGs from lignocellulose-derived sugars. Consequently, bacteria are now being considered as one of the more promising TAG sources for producing lipid-based biofuels since they have the following favorable qualities: a fast growth rate, ease of culturability, and the property of being a renewable source of biomass [100,104,116,117]. Whereas the accumulation of TAGs is a characteristic of few bacteria, one of particular interest would be R. opacus PD630, where intracellular lipid contents can reach more than $70 \%$ of the total cellular dry weight in cells grown on gluconate or olive-oil as the sole carbon source under growth-restricted conditions. Research on this particular strain has been ongoing since the mid-1990's [7]. Recently, it has been demonstrated that $R$. opacus PD630 has an acceptable feasibility for industrial fermentations in which high concentrations of glucose are used, as described above. There are global research efforts concerning 
the accumulation of TAGs in bacteria, and the expression and activities of many genes related to fatty acid synthesis are newly understood as of today [118-122]. It would seem easy to modify a bacterium's performance to improve its TAG accumulation on lignocellulosic biomass and establish a cost-effective consolidated bioprocess. However, there are some difficulties that have hindered the achievement of lower production costs on the large scale. Lignocellulose is an abundant and underutilized renewable feedstock, but it is a complex of rigid cellulose fibers embedded in a cross-linked matrix of lignin and hemicellulose that bind the fibers. For the conversion of lignocellulosic biomass to TAGs, the cellulose and hemicelluloses must be broken down into their corresponding monosaccharides so that bacteria can utilize them for growth and lipid production [123-125]. One of the major challenges to overcome is the presence of cell growth inhibitors generated during the treatment step of lignocellulosic biomass [126]. The presence of lignin in lignocellulosic hydrolysates leads to growth inhibition of $R$. opacus. It has been reported that $R$. opacus PD630 is able to break down some lignin-derived compounds, whereas Figure 7 shows that certain components of a relatively high concentration, probably lignin, present in the lignocellulosic hydrolysate inhibits cell growth [127]. Higher starting sugar concentrations in the medium result in maximizing the volumetric productivity and the efficiency of the fermentation, resulting in a lower cost process. At present, it might be difficult to prepare a lignocellulose-derived sugar solution greater than $200 \mathrm{~g} / \mathrm{L}$ without the overabundance of growth inhibitors in a cost-effective manner [128]. To alleviate this inhibition problem, genetic engineering could be employed to provide increased lignin tolerance to R. opacus PD630. A combination of inhibitor-tolerant strains along with the desired properties for detoxification of lignocellulose hydrolysates will likely improve of lignocellulose-to-TAG production process. Furthermore, genetic modifications should be investigated to extend the substrate utilization range of the strain, which could permit the utilization of cheaper, renewable substrates for biosynthesis of TAGs.

Bacterial TAG production at industrial scale is not economically feasible as of now due to its high processing costs and low productivity of the bioprocesses. To overcome these obstacles, highly productive strains need to be engineered and optimized for high oil productivity on lignocellulose-derived sugars, and development of effective and economical cultivation systems as well as separation and harvesting of biomass and oil will have to be investigated intensively. We believe that an engineered $R$. opacus strain can contribute to the ultimate goal of producing scalable and cost-effective advanced liquid biofuels.

\section{Acknowledgements}

This study was financially supported by MIT/Malaysia Biotechnology Partnership Programme (MMBPP), Shell Global Solution Inc., a seed grant from MIT Energy Initiative and Logos Technologies, Inc.

\section{References}

1. Madison LL, Huisman GW (1999) Metabolic engineering of poly(3hydroxyalkanoates): from DNA to plastic. Microbiol Mol Biol Rev 63: 21-53.

2. Steinbüchel A, Valentin HE (1995) Diversity of polyhydroxyalkanoic acids. FEMS Microbiol Lett 128: 219-228.

3. Alvarez HM, Steinbüchel A (2002) Triacylglycerols in prokaryotic microorganisms. Appl Microbiol Biotechnol 60: 367-376.

4. Wältermann M, Steinbüchel A (2005) Neutral lipid bodies in prokaryotes: recent insights into structure, formation, and relationship to eukaryotic lipid depots. J Bacteriol 187: 3607-3619

5. Preiss J, Romeo T (1989) Physiology, biochemistry and genetics of bacterial glycogen synthesis. Adv Microb Physiol 30: 183-238.
6. Peoples OP, Sinskey AJ (1989) Poly-beta-hydroxybutyrate (PHB) biosynthesis in Alcaligenes eutrophus $\mathrm{H} 16$. Identification and characterization of the PHB polymerase gene (phbC). J Biol Chem 264: 15298-15303.

7. Alvarez HM, Mayer F, Fabritius D, Steinbüchel A (1996) Formation of intracytoplasmic lipid inclusions by Rhodococcus opacus strain PD630. Arch Microbiol 165: 377-386.

8. Jendrossek D (2009) Polyhydroxyalkanoate granules are complex subcellular organelles (carbonosomes). J Bacteriol 191: 3195-3202.

9. Rehm BH (2003) Polyester synthases: natural catalysts for plastics. Biochem J 376: 15-33.

10. Kadouri D, Jurkevitch E, Okon Y, Castro-Sowinski S (2005) Ecological and agricultural significance of bacterial polyhydroxyalkanoates. Crit Rev Microbio 31: 55-67.

11. Li P, Chakraborty S, Stubbe J (2009) Detection of covalent and noncovalent intermediates in the polymerization reaction catalyzed by a C149S class III polyhydroxybutyrate synthase. Biochemistry 48: 9202-9211.

12. York GM, Stubbe J, Sinskey AJ (2002) The Ralstonia eutropha PhaR protein couples synthesis of the PhaP phasin to the presence of polyhydroxybutyrate in cells and promotes polyhydroxybutyrate production. J Bacteriol 184: 59-66.

13. Hisano T, Tsuge T, Fukui T, Iwata T, Miki K, et al. (2003) Crystal structure of the $(\mathrm{R})$-specific enoyl-CoA hydratase from Aeromonas caviae involved in polyhydroxyalkanoate biosynthesis. J Biol Chem 278: 617-624.

14. Tsuge T, Hisano T, Taguchi S, Doi $Y$ (2003) Alteration of chain length substrate specificity of Aeromonas caviae R-enantiomer-specific enoyl-coenzyme A hydratase through site-directed mutagenesis. Appl Environ Microbiol 69: 48304836.

15. Pötter M, Madkour MH, Mayer F, Steinbüchel A (2002) Regulation of phasin expression and polyhydroxyalkanoate (PHA) granule formation in Ralstonia eutropha H16. Microbiology 148: 2413-2426.

16. Tian J, He A, Lawrence AG, Liu P, Watson N, et al. (2005) Analysis of transient polyhydroxybutyrate production in Wautersia eutropha $\mathrm{H} 16$ by quantitative Western analysis and transmission electron microscopy. J Bacteriol 187: 38253832.

17. Gerngross TU, Reilly P, Stubbe J, Sinskey AJ, Peoples OP (1993) Immunocytochemical analysis of poly-beta-hydroxybutyrate $(\mathrm{PHB})$ synthase in Alcaligenes eutrophus $\mathrm{H} 16$ : localization of the synthase enzyme at the surface of PHB granules. J Bacteriol 175: 5289-5293.

18. Maehara A, Taguchi S, Nishiyama T, Yamane T, Doi Y (2002) A repressor protein, PhaR, regulates polyhydroxyalkanoate (PHA) synthesis via its direct interaction with PHA. J Bacteriol 184: 3992-4002.

19. Yamada M, Yamashita K, Wakuda A, Ichimura K, Maehara A, et al. (2007) Autoregulator protein PhaR for biosynthesis of polyhydroxybutyrate $[\mathrm{P}(3 \mathrm{HB})]$ possibly has two separate domains that bind to the target DNA and $P(3 \mathrm{HB})$ Functional mapping of amino acid residues responsible for DNA binding. J Bacteriol 189: 1118-1127.

20. York GM, Lupberger J, Tian J, Lawrence AG, Stubbe J, et al. (2003) Ralstonia eutropha $\mathrm{H} 16$ encodes two and possibly three intracellular Poly[D-(-)-3hydroxybutyrate] depolymerase genes. J Bacteriol 185: 3788-3794

21. Pfeiffer D, Jendrossek D (2011) Interaction between poly(3-hydroxybutyrate) granule-associated proteins as revealed by two-hybrid analysis and identification of a new phasin in Ralstonia eutropha. Microbiology 157: 27952807.

22. Pfeiffer D, Wahl A, Jendrossek D (2011) Identification of a multifunctiona protein, PhaM, that determines number, surface to volume ratio, subcellular localization and distribution to daughter cells of poly(3-hydroxybutyrate) $\mathrm{PHB}$, granules in Ralstonia eutropha H16. Mol Microbiol doi: 10.1111/j.13652958.2011.07869.x

23. MacEachran DP, Prophete ME, Sinskey AJ (2010) The Rhodococcus opacus PD630 heparin-binding hemagglutinin homolog TadA mediates lipid body formation. Appl Environ Microbiol 76: 7217-7225.

24. Budde CF, Riedel SL, Willis LB, Rha C, Sinskey AJ (2011) Production of Poly(3-Hydroxybutyrate-co-3-Hydroxyhexanoate) from Plant Oil by Engineered Ralstonia eutropha Strains. Appl Environ Microbiol 77: 2847-2854.

25. Horowitz D (2002) Methods for purifying polyhydroxyalkanoates. US Patent US 2002/0058316 A1. 
26. Anderson AJ, Dawes EA (1990) Occurrence, metabolism, metabolic role, and industrial uses of bacterial polyhydroxyalkanoates. Microbiol Rev 54: 450-472.

27. Anderson AJ, Haywood GW, Dawes EA (1990) Biosynthesis and composition of bacterial poly(hydroxyalkanoates). Int J Biol Macromol 12: 102-105.

28. Chen GQ (2009) A microbial polyhydroxyalkanoates (PHA) based bio- and materials industry. Chem Soc Rev 38: 2434-2446.

29. Holmes PA (1985) Applications of PHB - a microbially produced biodegradable thermoplastic. Phys Technol 16: 32-36.

30. Philip S, Keshavarz T, Roy I (2007) Polyhydroxyalkanoates: biodegradable polymers with a range of applications. J Chem Technol Biotechnol 82: 233-247.

31. Choi JI, Lee SY (1999) High-level production of poly(3-hydroxybutyrate-co-3hydroxyvalerate) by fed-batch culture of recombinant Escherichia coli. Appl Environ Microbiol 65: 4363-4368.

32. Choi JI, Lee SY, Han K (1998) Cloning of the Alcaligenes latus polyhydroxyalkanoate biosynthesis genes and use of these genes for enhanced production of Poly(3-hydroxybutyrate) in Escherichia coli. Appl Environ Microbiol 64: 4897-4903.

33. Wang F, Lee SY (1998) High cell density culture of metabolically engineered Escherichia coli for the production of poly(3-hydroxybutyrate) in a defined medium. Biotechnol Bioeng 58: 325-328.

34. Park SJ, Ahn WS, Green PR, Lee SY (2001) Production of poly(3hydroxybutyrate-co-3-hydroxyhexanoate) by metabolically engineered Escherichia coli strains. Biomacromolecules 2: 248-254.

35. Tian J, Sinskey AJ, Stubbe J (2005) Kinetic studies of polyhydroxybutyrate granule formation in Wautersia eutropha $\mathrm{H} 16$ by transmission electron microscopy. J Bacteriol 187: 3814-3824.

36. Wilde $E$ (1962) Unterschungen uber wachstum und speicherstoffsythese von Hydrogenomonas. Arch Mikrobiol 43: 109.

37. Tsuge T, Tanaka K, Ishizaki A (2001) Development of a novel method for feeding a mixture of L-lactic acid and acetic acid in fed-batch culture of Ralstonia eutropha for poly-D-3-hydroxybutyrate production. J Biosci Bioeng 91: $545-550$

38. Yang YH, Brigham CJ, Budde CF, Boccazzi P, Willis LB, et al. (2010) Optimization of growth media components for polyhydroxyalkanoate (PHA) production from organic acids by Ralstonia eutropha. Appl Microbiol Biotechnol 87: 2037-2045.

39. Brigham CJ, Budde CF, Holder JW, Zeng Q, Mahan AE, et al. (2010) Elucidation of beta-oxidation pathways in Ralstonia eutropha $\mathrm{H} 16$ by examination of global gene expression. J Bacteriol 192: 5454-5464.

40. Budde CF, Riedel SL, Hubner F, Risch S, Popovic MK, et al. (2011) Growth and polyhydroxybutyrate production by Ralstonia eutropha in emulsified plant oil medium. Appl Microbiol Biotechnol 89: 1611-1619.

41. Kahar P, Tsuge T, Taguchi K, Doi $Y$ (2004) High yield production of polyhydroxyalkanoates from soybean oil by Ralstonia eutropha and its recombinant strain. Polym Degrad Stab 83: 79-86.

42. Ng K-S, Ooi W-Y, Goh L-K, Shenbagarathai R, Sudesh K (2010) Evaluation of jatropha oil to produce poly(3-hydroxybutyrate) by Cupriavidus necator $\mathrm{H} 16$. Polym Degrad Stab 95: 1365-1369.

43. Riedel SL, Bader J, Brigham CJ, Budde CF, Yusof ZA, et al. (2011) Production of poly(3-hydroxybutyrate-co-3-hydroxyhexanoate) by Ralstonia eutropha in high cell density palm oil fermentations. Biotechnol Bioeng. doi: 10.1002/ bit.23283.

44. Volova TG, Kalacheva GS, Altukhova OV (2001) Autotrophic synthesis of polyalkanoates by Alcaligenes eutrophus in the presence of carbon monoxide. Mikrobiologia 70: 745-752.

45. Volova TG, Voinov NA (2003) Kinetic parameters of a culture of the hydrogenoxidizing Ralstonia eutropha, grown under the regimen of biosynthesis of polyhydroxybutyrate. Prikl Biokhim Mikrobiol 39: 189-193.

46. Kim BS, Lee SC, Lee SY, Chang HN, Chang YK, et al. (1994) Production of poly(3-hydroxybutyric acid) by fed-batch culture of Alcaligenes eutrophus with glucose concentration control. Biotechnol Bioeng 43: 892-898.

47. Ryu HW, Hahn SK, Chang YK, Chang HN (1997) Production of poly(3hydroxybutyrate) by high cell density fed-batch culture of Alcaligenes eutrophus with phospate limitation. Biotechnol Bioeng 55: 28-32.
48. Du G, Chen J, Yu J, Lun S (2001) Continuous production of poly-3hydroxybutyrate by Ralstonia eutropha in a two-stage culture system. Biotechnol 88: 59-65.

49. Shang L, Jiang M, Chang HN (2003) Poly(3-hydroxybutyrate) synthesis in fedbatch culture of Ralstonia eutropha with phosphate limitation under different glucose concentrations. Biotechnol Lett 25: 1415-1419.

50. Madden LA, Anderson AJ (1998) Synthesis and Characterization of Poly(3hydroxybutyrate) and Poly(3-hydroxybutyrate-co-3-hydroxyvalerate) Polymer Mixtures Produced in High-Density Fed-Batch Cultures of Ralstonia eutropha (Alcaligenes eutrophus). Macromolecules 31: 5660-5667

51. Lee SH, Oh DH, Ahn WS, Lee Y, Choi J, et al. (2000) Production of poly(3hydroxybutyrate-co-3-hydroxyhexanoate) by high-cell-density cultivation of Aeromonas hydrophila. Biotechnol Bioeng 67: 240-244.

52. Chen GQ, Zhang G, Park SJ, Lee SY (2001) Industrial scale production of poly(3-hydroxybutyrate-co-3-hydroxyhexanoate). Appl Microbiol Biotechnol 57 50-55.

53. Diniz SC, Taciro MK, Gomez JG, da Cruz Pradella JG (2004) High-celldensity cultivation of Pseudomonas putida IPT 046 and medium-chainlength polyhydroxyalkanoate production from sugarcane carbohydrates. App Biochem Biotechnol 119: 51-70.

54. Lee SY, Wong HH, Choi J, Lee SH, Lee SC, et al. (2000) Production of medium-chain-length polyhydroxyalkanoates by high-cell-density cultivation of Pseudomonas putida under phosphorus limitation. Biotechnol Bioeng 68 : 466-470.

55. Ishizaki A, Tanaka K, Taga N (2001) Microbial production of poly-D-3hydroxybutyrate from $\mathrm{CO}_{2}$. Appl Microbiol Biotechnol 57: 6-12.

56. Volova T, Gitelson J, Terskov I, Sidko F (1999) Hydrogen bacteria as a potentia regenerative LSS component and producer of ecologically clean degradable plastic. Life Support Biosph Sci 6: 209-213.

57. Braunegg G, Genser K, Bona R, Haage G, Schellauf F, et al. (1999) Production of PHAs from agricultural waste material. Macromol Symp 144: 375-383.

58. Cavalhiero JMBT, Almeida MCMDd, Grandfils C, Fonseca MMRd (2009) Poly(3-hydroxybutyrate) production by Cupriavidus necator using waste glycerol. Proc Biochem 44: 509-515.

59. Dionisi D, Carucci G, Papini MP, Riccardi C, Majone M, et al. (2005) Olive oil mill effluents as a feedstock for production of biodegradable polymers. Water Res 39: 2076-2084.

60. Hassan MA, Nawata O, Shirai Y, Rahman NAA, Yee PL, et al. (2002) A proposal for zero emission from palm oil industry incorporating the production of polyhydroxyalkanoates from palm oil mill effluent. J Chem Eng Jpn 35: 9-14.

61. Koller M, Bona R, Braunegg G, Hermann C, Horvat P, et al. (2005) Production of polyhydroxyalkanoates from agricultural waste and surplus materials. Biomacromolecules 6: 561-565.

62. Gouda MK, Omar SH, Aouad LM (2008) Single cell oil production by Gordonia sp. DG using agroindustrial wastes. World J Microbiol Biotechnol 24: 1703 1711.

63. Wong HH, Lee SY (1998) Poly-(3-hydroxybutyrate) production from whey by high-density cultivation of recombinant Escherichia coli. Appl Microbiol Biotechnol 50: 30-33.

64. Page WJ, Manchak J, Rudy B (1992) Formation of poly(hydroxybutyrate-cohydroxyvalerate) by Azotobacter vinelandii UWD. Appl Environ Microbiol 58 2866-2873.

65. Dias JM, Lemos PC, Serafim LS, Oliveira C, Eiroa M, et al. (2006) Recent advances in polyhydroxyalkanoate production by mixed aerobic cultures: from the substrate to the final product. Macromol Biosci 6: 885-906.

66. Salehizadeh H, Van Loosdrecht MC (2004) Production of polyhydroxyalkanoates by mixed culture: recent trends and biotechnological importance. Biotechno Adv 22: 261-279.

67. Beun JJ, Paletta F, Van Loosdrecht MC, Heijnen JJ (2000) Stoichiometry and kinetics of poly-beta-hydroxybutyrate metabolism in aerobic, slow growing, activated sludge cultures. Biotechnol Bioeng 67: 379-389.

68. Beun JJ, Verhoef EV, Van Loosdrecht MC, Heijnen JJ (2000) Stoichiometry and kinetics of poly-beta-hydroxybutyrate metabolism under denitrifying conditions in activated sludge cultures. Biotechnol Bioeng 68: 496-507. 
69. Satoh H, Mino T, Matsuo T (1999) PHA production by activated sludge. Int $\mathrm{J}$ Biol Macromol 25: 105-109

70. Majone M, Masanisso P, Carucci A, Lindrea K, Tandoi V (1996) Influence of storage on kinetic selection to control aerobic filamentous bulking. Water Sci Technol 34: 223-232.

71. Serafim LS, Lemos PC, Albuquerque MG, Reis MA (2008) Strategies for PHA production by mixed cultures and renewable waste materials. Appl Microbiol Biotechnol 81: 615-628.

72. Choi J, Lee SY (1999) Efficient and economical recovery of poly(3hydroxybutyrate) from recombinant Escherichia coli by simple digestion with chemicals. Biotechnol Bioeng 62: 546-553.

73. Dong Z, Sun X (2000) A new method of recovery polyhydroxyalkanoate from Azotobacter chroococcum. Chinese Sci Bull 45: 252-256.

74. Ramsay JA, Berger E, Voyer R, Chavarie C, Ramsay BA (1994) Extraction of poly-3-hydroxybutyrate using chlorinated solvents. Biotechnol Techn 8: 589 594.

75. Kurdikar DL, Strauser FE, Solodar AJ, Paster MD, Asrar J (2000) Methods of PHA extraction and recovery using non-halogenated solvents. US Patent: 6043063.

76. Kim M, Cho KS, Ryu HW, Lee EG, Chang YK (2003) Recovery of poly(3hydroxybutyrate) from high cell density culture of Ralstonia eutropha by direct addition of sodium dodecyl sulfate. Biotechnol Lett 25: 55-59.

77. Yang YH, Brigham C, Willis L, Rha C, Sinskey A (2011) Improved detergentbased recovery of polyhydroxyalkanoates (PHAs). Biotechnol Lett 33: 937-942

78. Yasotha K, Aroua MK, Ramachandran KB, Tan IKP (2006) Recovery of medium-chain-length polyhydroxyalkanoates (PHAs) through enzymatic digestion treatments and ultrafiltration. Biochem Eng J 30: 260-268.

79. Martinez V, Garcia P, Garcia JL, Prieto MA (2011) Controlled autolysis facilitates the polyhydroxyalkanoate recovery in Pseudomonas putida KT2440. Microb Biotechnol 4: 533-547.

80. van Hee P, Elumbaring AC, van der Lans RG, Van der Wielen LA (2006) Selective recovery of polyhydroxyalkanoate inclusion bodies from fermentation broth by dissolved-air flotation. J Colloid Interface Sci 297: 595-606

81. Yen CL, Stone SJ, Koliwad S, Harris C, Farese RV Jr (2008) Thematic review series: glycerolipids. DGAT enzymes and triacylglycerol biosynthesis. J Lipid Res 49: 2283-2301.

82. Durrett TP, Benning C, Ohlrogge J (2008) Plant triacylglycerols as feedstocks for the production of biofuels. Plant J 54: 593-607.

83. Murphy DJ (2001) The biogenesis and functions of lipid bodies in animals, plants and microorganisms. Prog Lipid Res 40: 325-438.

84. Lestari S, Maki-Arvela P, Beltramini J, Lu GQ, Murzin DY (2009) Transforming triglycerides and fatty acids into biofuels. ChemSusChem 2: 1109-1119.

85. Ali Y, Hanna MA (1994) Alternative diesel fuels from vegetable oils. Bioresour Technol 50: 153-163

86. Ryan III, TW, Dodge LG, Callahan TJ (1984) The effects of vegetable oil properties on injection and combustion in two different diesel engines. JAOCS 61: 1610-1619.

87. Manzanera M, Molina-Munoz ML, González-Lòpez J (2008) Biodiesel: An alternative fuel. Recent Patents on Biotechnology 2: 25-34.

88. Hill J, Nelson E, Tilman D, Polasky S, Tiffany D (2006) Environmental, economic, and energetic costs and benefits of biodiesel and ethanol biofuels. Proc Natl Acad Sci U S A 103: 11206-11210.

89. Jarboe LR, Grabar TB, Yomano LP, Shanmugan KT, Ingram LO (2007) Development of ethanologenic bacteria. Adv Biochem Eng Biotechnol 108: 237-261

90. Yan Y, Liao JC (2009) Engineering metabolic systems for production of advanced fuels. J Ind Microbiol Biotechnol 36: 471-479.

91. Ma F, Hanna MA (1999) Biodiesel production: a review. Bioresour Technol 70: 1-15.

92. Canakci M, Gerpen JV (2001) Biodiesel production from oils and fats with high free fatty acids. Trans ASAE 44: 1429-1436.

93. Azócar L, Ciudad G, Heipieper HJ, Navia R (2010) Biotechnological processes for biodiesel production using alternative oils. Appl Microbiol Biotechnol 88: 621-636.

94. Canakci M, Sanli H (2008) Biodiesel production from various feedstocks and their effects on the fuel properties. J Ind Microbiol Biotechnol 35: 431-441.

95. Knothe G (2010) Biodiesel and renewable diesel: A comparison. Prog Energy Comb Sci 36: 364-373.

96. Vasudevan PT, Briggs M (2008) Biodiesel production--current state of the art and challenges. J Ind Microbiol Biotechnol 35: 421-430.

97. Myllyoja J, Aalto P, Savolainen P, Purola VM, Alopaeus V, et al. (2011) Process for the manufacture of diesel range hydrocarbons. US Patent: US008022258B2.

98. Strege JR, Oster BG, Pansegrau PD, Wocken CA, Aulich TR (2011) Process for the conversion of renewable oils to liquid transportation fuels. US Patent US007989691B2.

99. Fairley P (2011) Introduction: Next generation biofuels. Nature 474: S2-5.

100. Meng X, Yang J, Xu X, Zhang L, Nie Q, et al. (2009) Biodiesel production from oleaginous microorganisms. Renewable Energy 34: 1-5

101. Olukoshi ER, Packter NM (1994) Importance of stored triacylglycerols in Streptomyces: possible carbon source for antibiotics. Microbiology 140: 931943.

102. ManillaPerez E, Lange AB, Luftmann H, Robenek H, Steinbüchel A (2011) Neutral lipid production in Alcanivorax borkumensis SK2 and other marine hydrocarbonoclastic bacteria. Eur J Lipid Sci Technol 113: 8-17.

103. Kalscheuer R, Stoveken T, Malkus U, Reichelt R, Golyshin PN, et al. (2007) Analysis of storage lipid accumulation in Alcanivorax borkumensis: Evidence for alternative triacylglycerol biosynthesis routes in bacteria. J Bacteriol 189 918-928.

104. Kosa M, Ragauskas AJ (2011) Lipids from heterotrophic microbes: advances in metabolism research. Trends Biotechnol 29: 53-61.

105. Santala S, Efimova E, Kivinen V, Larjo A, Aho T, et al. (2011) Improved triacylglycerol production in Acinetobacter baylyi ADP1 by metabolic engineering. Microb Cell Fact 10: 36

106. Voss I, Steinbüchel A (2001) High cell density cultivation of Rhodococcus opacus for lipid production at a pilot-plant scale. Appl Microbiol Biotechnol 55 547-555.

107.Stein K (2007) Food vs biofuel. J Am Diet Assoc 107: 1870, 1872-1876, 1878

108. Tollefson J (2008) Energy: not your father's biofuels. Nature 451: 880-883.

109. Kurosawa K, Boccazzi P, de Almeida NM, Sinskey AJ (2010) High-cell-density batch fermentation of Rhodococcus opacus PD630 using a high glucose concentration for triacylglycerol production. J Biotechnol 147: 212-218.

110. Riesenberg D, Guthke R (1999) High-cell-density cultivation of microorganisms Appl Microbiol Biotechnol 51: 422-430.

111. Teixeira MC, Raposo LR, Palma M, Sa-Correia I (2010) Identification of genes required for maximal tolerance to high-glucose concentrations, as those present in industrial alcoholic fermentation media, through a chemogenomics approach. OMICS 14: 201-210.

112. Du W, Li W, Sun T, Chen X, Liu D (2008) Perspectives for biotechnological production of biodiesel and impacts. Appl Microbiol Biotechnol 79: 331-337.

113. Chen CY, Yeh KL, Aisyah R, Lee DJ, Chang JS (2011) Cultivation, photobioreactor design and harvesting of microalgae for biodiesel production: a critical review. Bioresour Technol 102: 71-81.

114. Radakovits R, Jinkerson RE, Darzins A, Posewitz MC (2010) Genetic engineering of algae for enhanced biofuel production. Eukaryot Cell 9: 486501.

115. Singh A, Nigam PS, Murphy JD (2011) Mechanism and challenges in commercialisation of algal biofuels. Bioresour Technol 102: 26-34.

116. Li Q, Du W, Liu D (2008) Perspectives of microbial oils for biodiesel production. Appl Microbiol Biotechnol 80: 749-756.

117. Rude MA, Schirmer A (2009) New microbial fuels: a biotech perspective. Curr Opin Microbiol 12: 274-281.

118. Alvarez AF, Alvarez HM, Kalscheuer R, Wältermann M, Steinbüchel A (2008) Cloning and characterization of a gene involved in triacylglycerol biosynthesis 
Citation: Brigham CJ, Kurosawa K, Rha C, Sinskey AJ (2011) Bacterial Carbon Storage to Value Added Products. J Microbial Biochem Technol S3:002. doi:10.4172/1948-5948.S3-002

and identification of additional homologous genes in the oleaginous bacterium Rhodococcus opacus PD630. Microbiology 154: 2327-2335

119. Elbahloul Y, Steinbüchel A (2010) Pilot-scale production of fatty acid ethy esters by an engineered Escherichia coli strain harboring the $p$ (Microdiesel) plasmid. Appl Environ Microbiol 76: 4560-4565.

120. Hänisch J, Wältermann M, Robenek H, Steinbüchel A (2006) The Ralstonia eutropha $\mathrm{H} 16$ phasin $\mathrm{PhaP} 1$ is targeted to intracellular triacylglycerol inclusions in Rhodococcus opacus PD630 and Mycobacterium smegmatis mc2155, and provides an anchor to target other proteins. Microbiology 152: 3271-3280.

121. Hänisch J, Wältermann M, Robenek H, Steinbüchel A (2006) Eukaryotic lipid body proteins in oleogenous actinomycetes and their targeting to intracellular triacylglycerol inclusions: Impact on models of lipid body biogenesis. App Environ Microbiol 72: 6743-6750.

122. Steen EJ, Kang Y, Bokinsky G, Hu Z, Schirmer A, et al. (2010) Microbial production of fatty-acid-derived fuels and chemicals from plant biomass. Nature 463: 559-562.

123. Galbe M, Zacchi G (2007) Pretreatment of lignocellulosic materials for efficient bioethanol production. Adv Biochem Eng Biotechnol 108: 41-65.

124. Kumar P, Barrett DM, Delwiche MJ, Stroeve P (2009) Methods for pretreatment of lignocellulosic biomass for efficient hydrolysis and biofuel production. Ind Eng Chem Res 48: 3713-3729.

125. Margeot A, Hahn-Hagerdal B, Edlund M, Slade R, Monot F (2009) New improvements for lignocellulosic ethanol. Curr Opin Biotechnol 20: 372-380.
126. Parawira W, Tekere $M$ (2011) Biotechnological strategies to overcome inhibitors in lignocellulose hydrolysates for ethanol production: review. Crit Rev Biotechnol 31: 20-31.

127.Plaggenborg R, Overhage J, Loos A, Archer JA, Lessard P, et al. (2006) Potential of Rhodococcus strains for biotechnological vanillin production from ferulic acid and eugenol. Appl Microbiol Biotechnol 72: 745-755.

128. Roche CM, Dibble CJ, Stickel JJ (2009) Laboratory-scale method fo enzymatic saccharification of lignocellulosic biomass at high-solids loadings. Biotechnol Biofuels 2: 28.

129. Doi Y, Kitamura S, Abe H (1995) Microbial Synthesis and Characterization of Poly(3-hydroxybutyrate-co-3-hydroxyhexanoate). Macromolecules 28: 48224828.

130.Sudesh K, Abe H, Doi Y (2000) Synthesis, structure, and properties of polyhydroxyalkanoates: biological polyesters. Prog Polym Sci 25: 1503-1555.

131.Luo L, Wei X, Chen GQ (2009) Physical properties and biocompatibility of poly(3-hydroxybutyrate-co-3-hydroxyhexanoate) blended with poly(3hydroxybutyrate-co-4-hydroxybutyrate). J Biomater Sci Polym Ed 20: 15371553.

132. Saito Y, Doi Y (1994) Microbial synthesis and properties of poly(3 hydroxybutyrate-co-4-hydroxybutyrate) in Comamonas acidovorans. Int J Bio Macromol 16: 99-104. 